\title{
The Impact of EMPloyment Protection Mandates on Demographic Temporary EMPloyment PATterns: InTERnATIONAL Microeconomic EVIDENCE
}

by

\author{
Lawrence M. Kahn \\ Cornell University, Princeton University, CESifo and IZA
}

February 2005

Revised December 2005

*This is a revised version of a paper presented at the IZA Conference on Employment Protection and Labor Markets, Bonn, Germany, December 2-3, 2005. Comments are welcome. The author thanks Giuseppe Bertola, Daniel Hamermesh, Øivind Anti Nilsen and Conference participants for helpful comments and suggestions. 


\title{
THE IMPACT OF EMPloyment PRotection MANDATES ON DEMOgRAPHIC TEMPORARY EMPLOYMENT PATTERNS: INTERNATIONAL MICROECONOMIC EVIDENCE
}

\begin{abstract}
Using 1994-98 International Adult Literacy Survey (IALS) microdata, this paper investigates the impact of employment protection laws on the incidence of temporary employment by demographic group. More stringent employment protection for regular jobs is predicted to increase the relative incidence of nonemployment and temporary employment among employees for less experienced and less skilled individuals. I test this reasoning using IALS data for Canada, Finland, Italy, the Netherlands, Switzerland, the United Kingdom and the United States, countries with widely differing levels of mandated employment protection (EPL). Multinomial logit analyses (with nonemployment, temporary employment and permanent employment as the possible outcomes) find that the strength of such mandates (as measured by the OECD) is positively associated with the relative incidence of joblessness for younger individuals, women and immigrants, controlling for demographic factors and country-specific effects affecting nonemployment, and temporary and permanent employment. Moreover, among wage and salary workers, EPL is positively associated with the relative incidence of temporary employment for young workers, native women, immigrant women and those with low cognitive ability. I subject these findings on the incidence of temporary employment among employees to a variety of robustness checks. For example, the effects largely hold up when I adjust for the possible sample selection due to the fact that employment to population ratios differ across countries, when I disaggregate the effects of the OECD employment protection index into its component parts, when I exclude countries with the highest or lowest levels of employment protection mandates, and when I exclude those of school attendance age (16-25 years old). And, the effects of protection on the relative incidence of nonemployment for young and less skilled individuals, as well as the incidence of temporary employment among young, female, and immigrant employees are stronger in countries with higher levels of collective bargaining coverage. These patterns suggest a connection between binding wage floors and the allocative effects of employment protection mandates.
\end{abstract}

JEL Classification: J21, J23.

Keywords: employment protection, temporary jobs. 


\section{Introduction}

A considerable volume of economic research has been devoted over the last two decades to explaining and suggesting remedies for the stubbornly high unemployment rates in a number of European countries. Many authors have focused on labor market and other institutions as an important factor playing a role in influencing unemployment. ${ }^{1}$ These institutions include collective bargaining, employment protection mandates, restrictions on business entry, and mandated benefit programs such as unemployment insurance (UI) and disability programs, as well as the taxes levied to pay for them. Temporary employment contracts without mandated protection (or considerably less protection than exists on permanent jobs) have been used in a number of countries as an attempt to generate jobs that would not have been created and, therefore, as a policy designed to lower unemployment. It is sometimes argued that by allowing firms to create jobs with a fixed duration and with little or no termination costs, policies authorizing fixed term contracts increase the flexibility of labor markets made rigid by the institutions just mentioned. ${ }^{2}$ On the other hand, such policies may encourage firms to substitute temporary for permanent jobs thereby increasing the overall exit rate from jobs; the resulting higher turnover may even lead to higher unemployment than before, despite the new jobs created (Blanchard and Landier 2002).

While the ability of temporary contracts to lower the overall unemployment rate is uncertain, most analysts are agreed that more extensive employment protection mandates for permanent jobs increase incentives for firms to offer temporary jobs, and empirical research has found support for this prediction. ${ }^{3}$ This outcome is important since temporary jobs tend to be

\footnotetext{
${ }^{1}$ See Nickell and Layard (1999), Blanchard and Wolfers (2000), and Nickell, Nunziata and Ochel (2005).

2 A notable example is Spain, which in the 1980s and 1990s had extremely high unemployment rates and liberalized the use of temporary contracts in an attempt to generate jobs. See Dolado, Garcia-Serrano and Jimeno (2002).

${ }^{3}$ See, for example, Blanchard and Landier (2002), Cahuc and Postel-Vinay (2002), and Güell (2003) for theoretical models with this prediction. On the other hand, Lazear (1990) suggests that if wages are flexible, then to the extent that firing costs take the form of severance payments to workers, they need not raise the overall cost of offering permanent jobs. Instead, when there are high mandated firing costs, wages will adjust downward. Of course, if
} 
lower paying, and offer less training, other things equal, than permanent jobs; moreover, workers in temporary jobs express lower levels of job satisfaction than comparable workers in permanent jobs (Booth, Francesconi and Frank 2002). Thus, policies that lead to a substitution of temporary jobs for permanent jobs may actually worsen the welfare of the average worker, especially in the event that this policy doesn't lead to lower unemployment (Blanchard and Landier 2002; Cahuc and Postel-Vinay 2002).

The reasoning in such theoretical models suggests that the incidence of temporary jobs will not be randomly distributed across the labor force. Specifically, when there are substantial firing costs for permanent jobs, firms will be relatively reluctant to hire new entrants into such jobs. Instead, new entrants will be placed in temporary jobs where their productivity can be assessed before a permanent offer is made. New entrants disproportionately include the young, women and, possibly, immigrants.

This paper studies the impact of employment protection mandates on demographic patterns of temporary employment as well as nonemployment. As I show below, an extension of these theoretical models implies that higher firing costs for permanent jobs tend to widen the gap between the incidence of permanent jobs for experienced workers vs. recent entrants, as well as the gap in overall employment between these groups of workers. Moreover, suppose that wage floors constrain firms' ability to compensate for firing costs by offering lower wages. Then low wage workers such as the young, women, immigrants, and those with low cognitive skills will also be less likely to be able to obtain permanent jobs. These effects will again be larger the more expensive it is to fire someone from a permanent job. Further, to the extent that exits are more frequent from temporary than from permanent jobs, firing costs also are expected to raise the relative incidence of joblessness of less experienced and less skilled workers. To test this reasoning, I use the 1994-98 International Adult Literacy Surveys (IALS) microdata files, which

there are also mandated wage floors, or if employment protection regulation takes the form of wasteful procedures not resulting in payments to discharged workers, then wages are not likely to adjust downward to fully compensate firms for firing costs. Thus, the impact of firing costs for permanent jobs on the incidence of temporary jobs is to some degree an empirical question, and Booth, Dolado and Frank (2002) obtain aggregate evidence suggesting that employment protection does indeed raise the incidence of temporary employment. 
contain information on whether one was employed in a temporary or a permanent job and a variety of demographic information. In addition, the IALS contains cognitive skills data on these individuals from common tests, allowing one to make comparisons across countries in the effect of employment protection by skill level. ${ }^{4}$ The countries for which the IALS contains data allowing me to analyze these effects include Canada, Finland, Italy, the Netherlands, Switzerland, the United Kingdom and the United States. As I discuss further below, these countries differ widely in the extent to which they have enacted employment protection mandates, providing a high degree of variability in this key explanatory variable.

I find that across these countries, all else equal, the strength of employment protection mandates (EPL-as measured by the OECD) is positively associated with the relative incidence of joblessness among the young, immigrants, and women, controlling for demographic factors and country dummy variables. The EPL effects on the nonemployment of the young are stronger in countries with higher levels of collective bargaining coverage, and EPL has a negative interaction effect with collective bargaining coverage on the relative employment of the less skilled, as measured by both years of schooling and cognitive test scores. Moreover, I find that among wage and salary workers, stronger EPL raises the relative incidence of temporary employment for young workers, native women, and especially immigrant women, as predicted. And there is some evidence that protection has a disproportionate effect raising the incidence of temporary employment for those employed workers with low cognitive ability, an expected outcome to the extent that wage floors prevent pay from adjusting in response to mandated employment protection.

These results for the incidence of temporary employment among employed workers were subjected to a variety of robustness checks. For example, the basic results largely hold up when I adjust for the possible sample selection bias induced by the fact that employment to population ratios differ across countries. They also continue to hold when I disaggregate the OECD's employment protection index into its component parts: duration of mandated severance

\footnotetext{
${ }^{4}$ The IALS data are described in more detail below.
} 
payments; mandated compensation for unfair dismissal; length of mandatory notice in the event of layoffs; and an index of procedural inconvenience facing employers who wish to dismiss workers. The results also are robust to the exclusion of individual countries with the highest (Italy or the Netherlands) or the lowest levels of mandated employment protection (the United States) and when I exclude those of school attendance age (16-25 years old). And I further find that collective bargaining coverage has significantly negative interaction effects with employment protection on the relative incidence of permanent jobs for the young, immigrants, and women, as predicted by the wage floor reasoning mentioned above. These results provide evidence that labor market institutions disproportionately protect the jobs of prime age males, effects that are complementary to existing research which finds that the young and women are disproportionately disemployed or unemployed in heavily unionized societies, all else equal (Bertola, Blau and Kahn 2002).

\section{Employment Protection and Temporary Employment: Current Theory and Evidence}

Early theories of the impact of employment protection mandates emphasized that making it difficult or expensive to fire workers reduced firms' incentives to lay off workers and to create new jobs. Of course, as noted earlier, if wages are flexible, then firing costs can be capitalized in lower initial wages, leaving firms' incentives to offer new jobs unchanged, as long as firing costs take the form of actual severance payments to workers (Lazear 1990). However, if market imperfections such as wage floors or worker liquidity constraints prevent such a wage adjustment from occurring, then higher firing costs will lead to a greater disincentive to create jobs. Moreover, to the extent that employment protection mandates take the form of cumbersome regulations rather than payments to workers, there will again be a less than fully compensating decline in wages, although wages may well be affected in a general equilibrium sense. Under these circumstances, the net effect on the unemployment rate will be theoretically indeterminate, since firing costs will lower both layoffs and job creation (Bertola 1990, 1992). 
But, the negative effects on job creation are expected to be disproportionately felt by new entrants, while incumbent workers are most directly affected by the negative impact of employment protection mandates on layoffs. Bertola, Blau and Kahn (2002) in fact find that more extensive employment protection does disproportionately raise young men's and young women's unemployment rates, other things equal. And Autor, Donohue and Schwab (2004) find similar results for states in the US that have granted workers the right to sue for wrongful discharge. Specifically, the authors found that this type of wrongful discharge protection reduced state employment rates, with the largest effects for women, the young, and the less educated. As shown below, this same theme will inform my analysis of the impact of employment protection mandates on temporary employment.

More recent theories about employment protection recognize that firms have some rights to create temporary jobs which have a fixed duration and which can be terminated at the end of their term at relatively low cost or no cost at all. For example, Blanchard and Landier (2002) pose a model in which workers are hired into entry level, temporary jobs, and their productivity is observed by the firm. The firm then must decide whether to keep the worker in a permanent, regular job. Temporary jobs have lower firing costs than permanent jobs. The authors focus on the impact of lowering the firing costs of temporary jobs, while keeping the firing costs of permanent jobs the same, as occurred in France's recent reforms. Lower firing costs for temporary jobs or higher firing costs for permanent jobs both reduce the likelihood that a temporary job will be converted into a permanent one. ${ }^{5}$

Recent empirical research has examined the impact of firing costs on the incidence of temporary employment as well as the characteristics of such jobs and the workers in them. Specifically, Booth, Dolado and Frank (2002) use aggregate data to find that across 14 OECD countries for the 1980s and the 1990s, the fraction of employment that was in temporary jobs was significantly positively correlated with the OECD's index of strictness of regular employment protection mandates, as the theory outlined above predicts. However, the authors

\footnotetext{
${ }^{5}$ See Cahuc and Postel-Vinay (2002) and Güell (2003) for theoretical models with a similar prediction.
} 
also found that the incidence of temporary employment was significantly positively correlated with the strictness of temporary employment regulation as well, a finding that is not consistent with this theory. The resolution of this apparent paradox was found by estimating a multiple regression including both permanent and temporary protection mandate indexes on the right hand side. The results continued to show a significantly positive effect on temporary employment of permanent employment protection laws but no effect of temporary employment protection. The authors then suggest that regulations on temporary employment protection don't play a role in influencing the incidence of temporary jobs. Rather, the main factor is the strictness of permanent employment protection regulations. Within the US, similar results have been found for the overall impact of employment protection. Specifically, Autor (2003) concluded that a state's granting workers the right to sue over wrongful termination led to an increase in the temporary help services industry employment, all else equal.

In contrast to Booth, Dolado and Frank's (2002) findings that temporary employment regulations have no impact, Blanchard and Landier (2002) show that in France the transition probability from temporary to permanent jobs fell in the 1980s and the 1990s as the protections for temporary jobs were being relaxed, a prediction of the theory outlined above. Of course, the overall labor market was deteriorating in France at the same time, making a conclusion about the impact of the reforms tentative. Indeed, Holmlund and Storrie (2002) find that the recession in Sweden in the 1990 s was a major cause of the rise in the incidence of temporary employment there.

While not formally estimating the impact of firing costs on the relative incidence of temporary employment, the OECD (2002) and Petrongolo (2004) present some descriptive results on temporary jobs that are related to the present work. Specifically, the OECD (2002, p. 138) notes that among workers, temporary employment tends to be concentrated among the young, women, and the less educated. And Petrongolo (2004) finds that women tend be overrepresented in temporary work. 
In this paper, I extend existing theories and evidence on the impact of employment protection to examine its relative impact on different demographic groups. As discussed below, the basic theoretical setup in Blanchard and Landier (2002) can be shown to lead to a prediction that more stringent regulation of permanent employment tends to cause a higher gap in the incidence of permanent employment between recent labor market entrants and more experienced workers, as well as a higher relative incidence of joblessness among these workers. Moreover, I use microdata from several countries with varying degrees of employment protection strictness, allowing me to control for country-specific effects as well as observable heterogeneity across individuals in estimating the relative effects of protection mandates on temporary employment.

\section{Employment Protection and the Relative Incidence of Temporary Employment: Theoretical Considerations}

One can use the logic of Blanchard and Landier's (2002) model to study the impact of employment protection on the relative incidence of temporary employment and joblessness among recent labor market entrants and experienced workers. In Blanchard and Landier's (2002) model all entry level jobs start with the same productivity $\mathrm{y}_{0}$. Then after a period of unspecified duration, the firm receives an observation y on the worker's productivity. The firm then has the option of turning the job into a permanent one or terminating the worker and replacing him/her. Blanchard and Landier (2002) show that the firm's optimal policy is to set a threshold observed productivity level $\mathrm{y}^{*}$ above which the worker is kept in a permanent job and below which the worker is terminated. This is analogous to the reservation wage policy in models of job search. To analyze the impact of firing costs on the gap in the incidence of permanent work between new entrants and experienced labor market participants, let $\mathrm{c}_{\mathrm{p}}$ be firing

costs for a permanent job, $c_{t}$ be firing costs for a temporary job, and let $y^{*}\left(c_{p}, c_{t}\right)$ be the productivity threshold the firm requires in order to convert a temporary job to a permanent one, where $\partial \mathrm{y}^{*} / \partial \mathrm{c}_{\mathrm{p}}>0$ and $\partial \mathrm{y} * / \partial \mathrm{c}_{\mathrm{t}}<0$. 
Under these assumptions, the probability that a current spell of temporary employment is converted into a permanent job is:

1) $\operatorname{Prob}\left(y>y^{*}\left(c_{p}, c_{t}\right)\right)=1-F\left(y^{*}\left(c_{p}, c_{t}\right)\right)$,

where $\mathrm{F}(-)$ is the distribution function for productivity.

We may now compare the impact of firing costs for permanent jobs on the relative incidence of permanent and temporary employment of experienced workers who have been in the labor market for, say, $\mathrm{N}>1$ periods, and recent entrants who have been in the labor market for only one period. For simplicity, suppose initially that everyone is employed in each period, an assumption that will soon be relaxed. Then after one period in the labor market, the probability that a worker is still in a temporary job is:

2) Prob(temporary job $\mid$ one period of total experience $)=F\left(y^{*}\right)$,

suppressing the arguments of $y^{*}$. Following Blanchard and Landier's (2002) assumption that permanent jobs only end in retirement and that in each period, a worker in a new temporary job has the same probability of meeting the productivity threshold, the probability that one is in a temporary job after $\mathrm{N}$ periods of employment, assuming that retirement has not yet occurred is ${ }^{6}$ :

3) Prob (temporary job $\mid N$ periods of total experience $)=\left(F\left(y^{*}\right)\right)^{N}$.

From 1)-3), the impact of firing costs for permanent jobs on the relative incidence of temporary employment among recent entrants and those with $\mathrm{N}$ years of experience is:

4) $\quad \partial\left[\mathrm{F}\left(\mathrm{y}^{*}\right)-\left(\mathrm{F}\left(\mathrm{y}^{*}\right)\right)^{\mathrm{N}}\right] / \partial \mathrm{c}_{\mathrm{p}}=\mathrm{f}\left(\mathrm{y}^{*}\right) \partial \mathrm{y}^{*} / \partial \mathrm{c}_{\mathrm{p}}-\mathrm{NF}\left(\mathrm{y}^{*}\right)^{\mathrm{N}-1} \mathrm{f}\left(\mathrm{y}^{*}\right) \partial \mathrm{y}^{*} / \partial \mathrm{c}_{\mathrm{p}}$, where $\mathrm{f}(-)$ is the density function for $\mathrm{F}(-)$.

According to 4), a rise in $\mathrm{c}_{\mathrm{p}}$ lowers the relative probability of recent entrants' working in a permanent job (versus more experienced workers) if and only if:

\footnotetext{
${ }^{6}$ These assumptions are made for simplicity. Below, I discuss the implications of relaxing some of them.
} 
5) $0<\mathrm{f}\left(\mathrm{y}^{*}\right) \partial \mathrm{y}^{*} / \partial \mathrm{c}_{\mathrm{p}}-\mathrm{NF}\left(\mathrm{y}^{*}\right)^{\mathrm{N}-1} \mathrm{f}\left(\mathrm{y}^{*}\right) \partial \mathrm{y}^{*} / \partial \mathrm{c}_{\mathrm{p}}=\mathrm{f}\left(\mathrm{y}^{*}\right) \partial \mathrm{y}^{*} / \partial \mathrm{c}_{\mathrm{p}}\left[1-\mathrm{NF}\left(\mathrm{y}^{*}\right)^{\mathrm{N}-1}\right]$.

Since higher firing costs $c_{p}$ raise the threshold productivity level $y^{*}$, inequality 5) holds if and only if:

6) $\ln \mathrm{F}\left(\mathrm{y}^{*}\right)<\ln (1 / \mathrm{N}) /(\mathrm{N}-1)$.

By l'Hôpital's rule, the right hand side of 6) approaches zero (from below) as $\mathrm{N}$ gets large. As long as $\mathrm{F}\left(\mathrm{y}^{*}\right)<1$ (i.e. there is some positive probability that temporary jobs become extended into permanent jobs), eventually for large enough $\mathrm{N}, 6$ ) will hold. This result make intuitive sense, since for large $\mathrm{N}$, the probability that a worker with $\mathrm{N}$ periods of experience will not have landed a permanent job becomes arbitrarily low. Of course, if the $\mathrm{N}$ required to satisfy (6) is large relative to the length of one's work life, then higher $c_{p}$ may not raise the gap in permanent employment between experienced and inexperienced workers. Thus, whether (6) holds in reality is an empirical question, although the limit argument just outlined shows that it will hold asymptotically. From the result that $\partial \mathrm{y}^{*} / \partial \mathrm{c}_{\mathrm{t}}<0$, a fall in firing costs from temporary jobs has the same qualitative effect as a rise in firing costs from permanent jobs.

The scenario just described assumes that there is no on the job learning. Workers keep entering temporary jobs until they get a good enough productivity draw to induce their employer to convert the job into a permanent one. If workers acquire general human capital in these temporary jobs, then the conclusion that higher firing costs raise the difference in the incidence of temporary work between recent entrants and more experienced workers is reinforced. This is the case since more experienced workers who have only had temporary jobs up to now have more human capital than less experienced workers in temporary jobs. This implies that the instantaneous hazard for leaving a temporary for a permanent job rises with experience. This effect will be less important the more easily junior workers can get permanent jobs (i.e., the lower firing costs are).

The basic logic of this analysis of experience and the incidence of permanent work is that more experienced workers get more chances to land a permanent job, even if there is no on the job learning. One scenario in which this makes sense is one where the productivity draw is 
match-specific. If a worker doesn't get a good draw, this outcome does not prejudice future firms against the worker. However, it is also possible that future firms may take a worker's failure to secure a permanent job as a negative indicator of the worker's productivity. In an extreme case, this signal may be so strong as to eliminate the worker's future chances of getting a permanent job and thus make more experienced workers no more likely to qualify for a permanent job than less experienced workers. In this extreme case, everyone gets exactly one chance to qualify for a permanent job. Therefore, the incidence of permanent employment for those with one year of experience will be the same as the incidence with any level of experience greater than one. In such a case, high firing costs would have no effect on the experience gap in the incidence of permanent jobs. The intermediate case in which past failure to secure a permanent job provides some information to future employers about the current worker's productivity but where the worker still has a chance to eventually get a permanent job is perhaps more likely. In such a scenario, the probability of permanent employment could still approach one as experience rises and therefore higher firing costs could still raise the experience gap in permanent employment.

The above reasoning suggests that even if one is able to find a job every period, higher firing costs $c_{p}$ will eventually raise the experience gap in the incidence of permanent employment. I have assumed for simplicity that one is employed each period. In the likely event that it takes time to locate a job when one enters the labor market or has left a job, then we expect employment protection mandates to lower the relative propensity of inexperienced and low skill individuals to be employed, since the exit rate from temporary jobs is likely to be higher than the exit rate from permanent jobs. Finally, all of the predictions mentioned above become weaker the more downwardly-flexible starting wages are, using reasoning discussed earlier. Thus, the effects of EPL on joblessness and temporary employment among workers are expected to become stronger in countries with more downward wage rigidity.

\section{Institutional Setting and Data}


As noted earlier, I use 1994-98 IALS data for Canada, Finland, Italy, the Netherlands, Switzerland, the United Kingdom and the United States to study the impact of employment protection on the relative incidence of temporary employment among demographic groups. As Tables 1 and 2 indicate, these countries had very different regulations on job security in the 1990s. For example, Table 1 shows that Italy had much higher mandated severance pay both for no-fault dismissals and compensation for unfair dismissals than the other countries. The countries also differed with respect to the amount of notice a worker must be given before he/she can be dismissed, with employers in Finland being required to give 6 months notice, and those in the US not required to give any. Procedural delays were especially common in the Netherlands. Finally, the OECD provided an overall indicator of regular employment protection strictness, with Italy (2.8) and the Netherlands (3.1) at the top of my group of seven countries, followed by Finland at 2.1, with Switzerland, Canada and the UK in a group at 0.8-1.2, and the US with the least protection (0.2).

Table 2 shows the OECD's measures of regulation of temporary employment. In Canada, the UK and the US, there is no limit on the maximum number of fixed term contracts a firm is allowed to offer a worker. Italy is the only country in the group with a limit on the accumulated duration of fixed term contracts or any significant barriers to employment by temporary work agencies. Across countries, the overall temporary employment protection index and that for permanent employment have a correlation of 0.74 , which is significant at the $5.7 \%$ level, despite the presence of only seven observations. The similarity of the countries' rankings for their regulation of permanent and temporary employment will make it difficult to distinguish the effects of these two types of regulation.

I use the IALS microdata to study the effects of employment protection mandates on permanent employment. The IALS is the result of an international cooperative effort, conducted over the 1994-8 period, to devise an instrument to compare the cognitive skills of adults across a 
number of countries. ${ }^{7}$ Each country is represented by a single random cross-section taken in one year, with the exception of Switzerland, for which the German- and French-speaking subsamples were suveryed in 1994, while the Italian-speaking subsample was surveyed in 1998. The other countries' survey years were as follows: Canada, the Netherlands, and the US-1994; the UK1996; and Finland and Italy-1998. Because the design is a single cross-section, I am unable to analyze the frequency and duration of temporary employment. Rather, I in effect study the stock of temporary jobs, an analysis conceptually similar to studying the stock of unemployed workers. It should be noted that any national differences in the overall duration or frequency of temporary employment will be controlled for by the inclusion of country dummies in the basic models. The sampling frame was similar across countries, with the target population being those 16 years and older who were not in institutions or the military. ${ }^{8}$ In addition to test scores, data are available on gender, immigrant status, employment status including whether one was in a temporary or a regular job, schooling, age, industry, and occupation.

Of unique interest in the IALS is its measurement of cognitive skills. This was accomplished through three tests that were administered to all respondents in their respective home languages. These tests were designed to measure prose, document and quantitative literacy and are described in more detail in the Appendix. Although, in principle, interpreting prose or documents, and using mathematics may each require different skills, these skills, as measured by the IALS, are in fact highly correlated. Forming a score for each of the three tests (i.e., quantitative, prose, and document literacy) based on the average of the five available estimates, I found that these scores were correlated at roughly .9. Due to this high correlation, in the econometric work that follows, I report results based on a measure of cognitive skills which is an average of the three average test scores for each individual.

\footnotetext{
${ }^{7}$ For further description of the IALS, see OECD (1998) and USDOE, NCES (1998).

8 There were some geographic exclusions in some cases, but these were $3 \%$ or less of the target population, except for Switzerland, where the exclusion of Italian and Rhaeto-Romantic regions, persons in institutions and persons without telephones accounted for $11 \%$ of the total potential sample. In all cases, the IALS supplied a set of sampling weights, which I used in all analyses, after I adjusted each country's weights so that the total weight for each country was the same. See the IALS documentation file, available from Statistics Canada.
} 
Table A1 provides some descriptive information on the employment outcomes analyzed here, and Figures 1-4 show bivariate relationships between the OECD's EPL index for regular employment and the incidence of temporary employment in the IALS among wage and salary workers. Table A1 shows that in the population, the incidence of permanent work among men ranges from a low of $57 \%$ in Finland to $77 \%$ in the US, while for women the range is even greater-from $32 \%$ in Italy to $61 \%$ in the US. These figures of course combine both the incidence of work and the incidence of permanent jobs among those with work. The IALS figures for nonemployment are very highly correlated with those in the OECD (1999) for 1998: specifically, for the seven countries studied here, the IALS- and OECD-based nonemployment rates among men have a correlation of 0.88 , those for women are correlated at 0.83 , and the gender gap in joblessness is correlated at .90 in the two data sources.

Table A1 also shows the incidence of temporary employment among wage and salary workers in the IALS and from the OECD (2002) for 2000. Overall, in both data sources, the US and the UK have a relatively low incidence of temporary work, and Finland has a high incidence. The figures from the two data sources are generally consistent with each other, although the correlation is less close than it is for joblessness: temporary employment for men is correlated at .57 in the two data sources and the correlation for women is .65. However, in both the OECD (2002) and IALS data, women are more likely to have temporary jobs than men do, and the gender gap in temporary is highly correlated in the two data sources at .76. ${ }^{9}$ It is of course possible that respondents interpreted questions about temporary work differently in the OECD data compared to the IALS. But the inclusion of country dummy variables in the empirical work to some degree can correct for such differences. The fact that the gender gap in temporary work is more highly correlated between the IALS and the OECD than the individual figures for men

\footnotetext{
${ }^{9}$ Excluding Italy, which has the largest divergence in temporary employment incidence between the two data sources, temporary employment is very highly correlated across the IALS and OECD: for men, the incidence has a correlation of 0.74 , for women, the correlation is 0.83 , and the gender gap is correlated at 0.91 . As discussed below, my basic econometric results for the incidence of temporary employment were very similar when Italy was excluded.
} 
and women suggests the usefulness of studying within country differences in temporary employment.

Figures 1-4 show bivariate relationships between the incidence of permanent employment and the OECD's overall indicator of regular employment protection mandates, stratified by gender, age, immigrant status, or cognitive test score level. The sample includes all individuals in the seven countries listed earlier who were employed as wage and salary workers. In each case, a regression line is included for each subgroup. Figure 1 shows declining incidence of permanent employment for both men and women as mandated employment protection becomes stricter. Of particular note is that the relationship is stronger for women than for men, at least as indicated by the steepness of the regression line. While women and men are roughly equally likely to have permanent jobs if employment protection is minimal, the predicted gap grows to about 8 percentage points (about 10\%) at the strictest employment protection levels. Figure 2 shows the relationship between permanent employment and employment protection for 16-25 year olds and 46-55 year olds. The employed young are substantially less likely than 4655 year olds to have a permanent job even when employment protection is minimal: the gap is roughly 10 percentage points. More importantly for the argument here, the gap grows substantially as employment protection increases. Specifically, while the incidence of permanent employment for $46-55$ year olds is very high at about $95 \%$ of employment and is uncorrelated with employment protection mandates, permanent employment for the young falls sharply when employment protection becomes more stringent. The latter ranges from about $85 \%$ when there is little protection to only $60 \%$ when protection is at its sample maximum.

Figure 3 shows the permanent employment-employment protection relationship broken down by immigrant status. The incidence of permanent employment falls for both natives and immigrants, with a steeper decline for immigrants. While the incidence is about $92-93 \%$ for immigrants and natives at low levels of employment protection, permanent employment falls to $85 \%$ for natives and about $73-74 \%$ for immigrants with high levels of protection. Finally, Figure 4 shows the permanent employment-protection relationship for those with low test scores, which 
are defined and described in the Appendix, and for others. I focus on those with low cognitive skills because they are most likely affected by wage floors. Figure 4 shows that individuals with low test scores have a slightly lower predicted incidence of permanent employment than others do at low levels of protection, with about a one percentage point gap. The difference widens with higher levels of protection to about four percentage points.

Figures 1-4 all convey a similar message: stronger employment protection mandates have a more negative relationship with the incidence of permanent employment for low skill groups or workers with less experience than for higher skill or more experienced workers. These relationships were predicted by the theoretical reasoning discussed above. However, while suggestive, none of the Figures control for other influences on permanent employment. The econometric analyses in the next sections will implement such controls.

\section{Empirical Procedures}

To investigate the impact of employment protection mandates, I initially estimate a multinomial logit model with a dependent variable that takes on three possible values: 1 for nonemployment, 2 for being employed in a temporary job, and 3 for being employed in a permanent job. This procedure allows one to simultaneously estimate the determinants of joblessness and the type of contract among those with jobs. Since it uses the entire adult population as the sample, the procedure avoids possible sample selection problems. The model can be summarized as follows:

7) $\operatorname{Prob}\left(\operatorname{Perm}_{\mathrm{ij}}=1 \mid \mathrm{Z}_{\mathrm{ij}}\right) / \operatorname{Prob}\left(\right.$ Nonemployed $\left._{\mathrm{ij}}=1 \mid \mathrm{Z}_{\mathrm{ij}}\right)=\exp \left(\mathrm{C}_{1}{ }^{\prime} \mathrm{Z}_{\mathrm{ij}}\right) \equiv \exp \left(\mathrm{B}_{1}{ }^{\prime} \mathrm{X}_{\mathrm{ij}}+\mathrm{a}_{11}{ }^{*} \mathrm{EPL}_{\mathrm{j}}+\right.$

$$
\begin{aligned}
& \mathrm{a}_{12} * \mathrm{EPL}_{\mathrm{j}} * \mathrm{AGE}_{2635_{\mathrm{ij}}}+\mathrm{a}_{13} * \mathrm{EPL}_{\mathrm{j}} * \mathrm{AGE} 645_{\mathrm{ij}}+\mathrm{a}_{14} * \mathrm{EPL}_{\mathrm{j}} * \mathrm{AGE} 655_{\mathrm{ij}}+ \\
& \mathrm{a}_{15} * \mathrm{EPL}_{\mathrm{j}} * \mathrm{AGE}_{5665_{\mathrm{ij}}}+\mathrm{a}_{16} * \mathrm{EPL}_{\mathrm{j}} * \mathrm{EDYRS}_{\mathrm{ij}}+\mathrm{a}_{17} * \mathrm{EPL}_{\mathrm{j}} * \mathrm{LEVEL}_{\mathrm{ij}}+ \\
& \left.\mathrm{a}_{18} * \mathrm{EPL}_{\mathrm{j}} * \mathrm{FEMALE}_{\mathrm{ij}}+\mathrm{a}_{19} * \mathrm{EPL}_{\mathrm{j}} * \mathrm{IMMIG}_{\mathrm{ij}}\right)
\end{aligned}
$$


8) $\operatorname{Prob}\left(\operatorname{Perm}_{\mathrm{ij}}=1 \mid \mathrm{Z}_{\mathrm{ij}}\right) \operatorname{Prob}\left(\operatorname{Temp}_{\mathrm{ij}}=1 \mid \mathrm{Z}_{\mathrm{ij}}\right)=\exp \left(\mathrm{C}_{2}{ }^{\prime} \mathrm{Z}_{\mathrm{ij}}\right) \equiv \exp \left(\mathrm{B}_{2}{ }^{\prime} \mathrm{X}_{\mathrm{ij}}+\mathrm{a}_{21}{ }^{*} \mathrm{EPL}_{\mathrm{j}}+\right.$

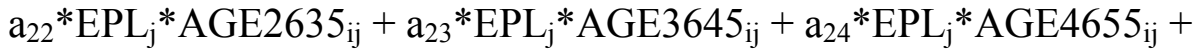

$$
\begin{aligned}
& \mathrm{a}_{25} * \mathrm{EPL}_{\mathrm{j}} * \mathrm{AGE}_{6665_{\mathrm{ij}}}+\mathrm{a}_{26} * \mathrm{EPL}_{\mathrm{j}} * \mathrm{EDYRS}_{\mathrm{ij}}+\mathrm{a}_{27}{ }^{*} \mathrm{EPL}_{\mathrm{j}} * \operatorname{LEVEL}_{\mathrm{ij}}+ \\
& \left.\mathrm{a}_{28} * \mathrm{EPL}_{\mathrm{j}}^{*} \text { FEMALE }_{\mathrm{ij}}+\mathrm{a}_{29} * \mathrm{EPL}_{\mathrm{j}}{ }^{*} \mathrm{IMMIG}_{\mathrm{ij}}\right) \text {, }
\end{aligned}
$$

where for each person $\mathrm{i}$ in country $\mathrm{j}$ between 16 and 65 years old, Perm is a dummy variable equaling one if one is employed in a permanent job; Nonemployed is a dummy variable equaling one if one is not employed; Temp is a dummy variable equaling one if one is employed in a temporary job; $\mathrm{X}$ is a vector of explanatory variables to be described; EPL is the country's OECD permanent employment protection indicator; AGE2635-AGE5665 are a series of dummy variables for age in the ranges $26-35,36-45,46-55$, and $56-65$ respectively (16-25 years old is the omitted age category) ${ }^{10}$; EDYRS is years of schooling; LEVEL1 is a dummy variable for having average IALS test score in the LEVEL 1 (lowest) range; FEMALE is a female dummy variable; IMMIG is an immigrant dummy variable; and $\mathrm{Z}$ is a vector including all of these explanatory variables.

The explanatory variables in $\mathrm{X}$ include main effects for the four age group dummies just mentioned, years of schooling, low test score, gender, and immigrant status, as well as a full set of interactions of gender and the age, education, low test score and immigrant variables. Coefficients $\mathrm{a}_{12}-\mathrm{a}_{19}$ and $\mathrm{a}_{22}-\mathrm{a}_{29}$ test the hypothesis that employment protection has different effects on the indicated demographic or skill group. Main effects $\mathrm{a}_{11}$ and $\mathrm{a}_{22}$ are included, which give the impact of employment protection when the age, education, gender, test score and immigrant status variables all equal zero. Moreover, the model was estimated adjusting the IALS individual sampling weights so that each country receives the same total weight, and the asymptotic standard errors are corrected for clustering within countries.

A challenge in doing international comparative labor market research is that many institutions occur in clusters, and it may be difficult to pinpoint the effect of one institution such

\footnotetext{
${ }^{10}$ I adopted this age specification because the IALS age data for Canada were only available in categorical form.
} 
as employment protection across a sample of OECD countries (Bertola, Blau and Kahn 2002). With only seven countries to work with here, it is not possible to control for the full set of other institutions that could potentially affect the incidence of permanent employment. But, since the key effects I am interested in are the interactions between protection and demographic or skill variables, it is possible to replace the protection main effect with a series of country dummies. These summarize all other unmeasured influences on the incidence of nonemployment, permanent employment or temporary employment. These include but are not limited to other policies and institutions such as taxes, UI, collective bargaining, disability programs, and product market regulation, as well as the availability and quality of educational opportunities and population characteristics that influence employment outcomes. Therefore, some versions of the model were estimated with country dummies.

Even with country dummies, however, other institutions such as collective bargaining coverage may have indirect effects on the relative incidence of nonemployment or permanent employment across demographic or skill groups. For example, if unions compress wages (Blau and Kahn 1996), then collective bargaining may accentuate the effects of employment protection in shutting younger, female, immigrant or less skilled workers out of employment or out of permanent jobs. Therefore, in some models, I allow for interactions between employment protection and 1994 collective bargaining coverage and the demographic variables, as well as of course collective bargaining main effects, lower-level interactions between collective bargaining and the controls, and an interaction between collective bargaining and protection. ${ }^{11}$

The sample for estimating the multinomial logit model of course includes all individuals whether or not they are employed. This design therefore does not allow one to control for sector or type of employment in estimating the probability that one's job is temporary. Including occupation and industry can control for compositional differences across countries. If, for example, countries with stricter employment protection laws also have relatively large sectors in which temporary work is common for reasons other than mandated protection, then failure to

${ }^{11}$ Collective bargaining coverage information is taken from OECD (1997). 
control for sector may produce a spurious negative relationship between protection and permanent jobs. This example illustrates the value of using microdata, which allow one to control for compositional factors. In addition, the theory of temporary protection outlined earlier is best applied to wage and salary workers, who have employers making decisions about whether to keep them, and self-employed workers may interpret a question about temporary employment differently from wage and salary workers. I therefore additionally estimate the determinants that one's job is permanent given that one is a wage and salary worker, using a logit model with the same controls as in equations 7) and 8), augmented by a vector of industry and occupation dummy variables and their interactions with a female dummy variable. ${ }^{12}$ This design allows one to control for sector and type of employment. On the other hand, employment protection laws may themselves lead to changes in the relative sizes of sectors if they raise costs in some industries or occupations more than in others. In this scenario, the sectoral composition is part of the impact of employment protection laws. Thus, the multinomial logit results which of course do not control for sector can be seen as reduced forms where institutions affect the sizes of various sectors, as well as the individual's choices between employment and schooling.

As noted, restricting the sample to employed wage and salary workers allows one to focus on the theories discussed earlier and in effect control for labor supply and school enrollment choices that may be confounded with employment protection mandates. However, since the availability of schooling opportunities could affect the relative incidence of temporary employment among employed youth, particularly those with high cognitive ability levels who would be the most likely to enroll, I also test the robustness of the basic results to exclusion of those age 16-25 years old. This sample is not likely to be directly greatly affected by schooling

\footnotetext{
12 The industries are: 1. Agriculture, hunting, forestry and fishing; 2. Mining and quarrying; 3. Manufacturing; 4. Electricity, gas and water; 5. Construction; 6. Wholesale and retail trade; 7. Transport, storage and communication; 8. Finance, insurance, real estate and business services; and 9. Community, social and personal services. The occupations are: 1. Legislators, senior officials and managers; 2. Professionals; 3. Technicians and associate professionals; 4. Clerks; 5. Service workers and shop and market sales workers; 6. Skilled agricultural and fishery workers; 7. Craft and related trades workers; 8. Plant and machine operators and assemblers; and 9. Elementary occupations. In each case, category number 1 is the omitted category.
} 
opportunities and therefore provides an additional, sharper test of the basic hypotheses outlined above.

As discussed further below, I also attempted several other specifications in estimating the probability of permanent employment among wage and salary workers. First, in some models I also control for temporary employment regulation and its interactions with age, education, test score, gender and nativity status. Efforts to disentangle the effects of regular and temporary employment regulation must remain tentative, due to the previously-mentioned high correlation between permanent and temporary employment regulation. Second, I test whether the demographic effects of employment protection differ by gender. This might be expected, since women earn lower pay than men and are therefore more likely to be constrained by wage floors. Third, since the estimation sample consists of employed workers, I also address the issue of possible selection bias. For example, in countries where employment rates are relatively low, the employed workers may have particularly high work motivation or unmeasured skills (relative to the population as a whole) compared to countries with high employment rates. Workers with high levels of work motivation or unmeasured skills may be more likely than otherwise to obtain permanent employment. Since employment-population differences across countries are much larger for young people and women than for prime age males (Bertola, Blau and Kahn 2002), such selection issues may directly affect my protection-demographic group interactions. Therefore, as discussed in more detail below, in some specifications, I address this possible selection bias. Fourth, in some analyses, I disaggregate the OECD's overall protection index into its component parts, reflecting severance pay, unfair dismissal pay, mandatory notice of layoffs, and procedural delays. Finally, I investigated the sensitivity of the results to exclusion of countries with very high or very low levels of employment protection.

\section{Results: Full Sample of All Individuals}


Tables 3,4 and A2 contain multinomial logit results for the simultaneous analysis of nonemployment, temporary employment and permanent employment. Table 3, Panels A and B contain multinomial logit coefficients and risk ratios (i.e. the effect of the variable on the relative probability of the two indicated outcomes). Panels C and D show results for the "unconditional" (i.e., conditional only on the explanatory variables) probability of nonemployment or permanent employment which are implied by the multinomial logit coefficients. ${ }^{13}$ Looking first at nonemployment, Table 3, Panel $\mathrm{C}$ shows that employment protection raises the relative likelihood of employment for prime age vs. young individuals, men vs. women, and natives vs. immigrants. The results are similar whether or not I control for country dummies. ${ }^{14}$ The magnitudes are moderately large, particularly for age and immigrant status. Specifically, the units in Panel $\mathrm{C}$ are employment probability effects, and the impact of EPL on nonemployment for 36-45 year olds vs. 16-25 years, for example, ranges from -7.6 to -7.7 percentage points, and the average joblessness incidence for the sample, is about $36 \%$. Effects appear small for education and low test score, although the signs are opposite to what one would expect. Effects are somewhat larger for women and even more so for immigrants. Regarding statistical significance, the age interactions are highly significant as a group (although not individually), the EPL interactions with education and test score are insignificant to marginally significant, the EPL gender interactions are about 1.5 times their asymptotic standard errors, and EPL-immigrant interactions are highly significant. Overall, then, I find that stronger EPL lowers the relative employment of the young and immigrants, with a marginally negative effect on women.

As discussed earlier, if there are wage floors, then Lazear's (1990) analysis predicts that employment protection mandates will have even larger effects than otherwise in shutting out low

\footnotetext{
${ }^{13}$ For example, using equations (7) and (8), recalling that $\mathrm{Z}$ is the full set of explanatory variables, $\mathrm{C}_{1}$ is the full vector of coefficients for equation (7), and $C_{2}$ is the full vector of coefficients for equation (8), the probability that one is employed in a permanent job is:

$\operatorname{Prob}(\operatorname{Perm} \mid \mathrm{Z})=1 /\left(\exp \left(-\mathrm{C}_{1}{ }^{\prime} \mathrm{Z}\right)+\exp \left(-\mathrm{C}_{2}{ }^{\prime} \mathrm{Z}\right)\right)$. The other "unconditional" probabilities can be similarly calculated, and the partial derivatives of all of these probabilities with respect to the $Z$ variables can also be computed.

${ }^{14}$ Inclusion of country dummies implies of course that the main effect of employment protection can no longer be included.
} 
skill workers from employment generally or permanent employment. I tested this notion by adding a series of three way interactions between collective bargaining coverage, employment protection and the demographic and skill variables in the model. In addition, I added lower level interactions between collective bargaining coverage and the demographic/skill variables as well as a main collective bargaining coverage effect $(\mathrm{CB} \mathrm{Cov})$ and a (CB Cov)-EPL interaction. Table 4, Panel A shows that the negative EPL employment effects for youth become significantly larger in magnitude in countries with high levels of collective bargaining, effects which are also large in magnitude. ${ }^{15}$ Moreover, the EPL* $\mathrm{CB}$ Cov interaction effects for nonemployment are negative (and marginally significant) for schooling and positive (and marginally significant controlling for country dummies) for low test score. These results imply that EPL has a more negative effect on the relative employment of the less educated and the low skilled in countries with higher levels of collective bargaining coverage.

Tables 3, 4 and A2 also contain findings for the incidence of permanent employment, the primary focus of this paper. Table 3, Panels B and D show that stronger EPL raises the relative incidence of permanent employment relative to temporary employment (Panel B) or the rest of the population (Panel D) by more for prime age vs. young workers, men and natives. EPL also lowers the relative probability that employed workers with low test scores will have a permanent job. Again, the age interactions are highly significant as a group, the effects for women and immigrants are significant or marginally so, and the effects for those with low test score are significant conditional on employment (Table 3, Panel B). The magnitudes of these effects are again moderately large and similar absolutely to the effects on nonemployment (the incidence in the population of permanent employment is about $57 \%$ and temporary employment is $7 \%$ ). For example, Table 3, Panel D shows that EPL raises the relative likelihood that 36-45 year olds in the population will have a permanent job by 8.6 percentage points relative to $16-25$ year olds. The effects for men and immigrants are 3.7 and 7.1 percentage points, respectively.

15 Appendix Table A2 shows the raw multinomial coefficients upon which the entries in Table 4 are based. 
Tables 4 and A2 show that the EPL effects on permanent jobs for prime age vs. the young or EPL interaction effects with education are significantly larger in magnitude where collective bargaining coverage is higher, whether relative to the whole population (Table 4) or the employed (Table A2). And, Table A2, Panel B shows that EPL raises the relative probability of permanent vs. temporary employment for men and natives by significantly more in countries with high levels of collective bargaining coverage. As was the case for employment, these three way interaction effects are also large in magnitude. Finally, Table A2, Panel B shows the counterintuitive result of a positive EPL-collective bargaining coverage-Low Test Score interaction for permanent vs. temporary employment. Thus, the effects of skill level are somewhat ambiguous with opposite effects of schooling and test scores. But the findings for youth, women and immigrants do suggest that EPL and collective bargaining interact to lower these groups' incidence of finding a permanent job. The next section provides further evidence on the impact of protection mandates on permanent employment among wage and salary workers, allowing for a wider set of controls.

\section{Results: Employed Wage and Salary Workers}

\section{A. Basic Results}

Table 5 shows ordinary least squares (OLS) and logit analyses of the determinants of permanent employment, with the sample restricted to employed wage and salary workers. I vary the specifications in two ways: i) inclusion or exclusion of industry and occupation dummies and their interactions with gender; ii) inclusion or exclusion of country dummies. The logit results are the partial derivatives of the dependent variable evaluated at the sample mean incidence of permanent employment; the OLS results of course are already in probability units. Overall, Table 5 shows that all else equal, protection has more positive effects on permanent employment for older workers, those scoring above the lowest level on the IALS literacy tests, 
men and native born workers, as our earlier theoretical discussion predicted, and as found in the multinomial results for the whole population. The interaction effects are significant in almost every case for age (except for age 26-35 in the logits), in every case for gender, and usually significant or marginally so for literacy and immigrant status. Moreover, the interaction effects increase algebraically in each case with rising age beyond 35 , suggesting rising relative protection as workers age. ${ }^{16}$ The OLS results show a significant interaction effect for age 26-35, while the logits show a small and insignificant interaction for this group (relative of course to the 16-25 year old omitted group). Effects of education are never large in absolute value or statistically significant. It is reassuring that the basic results hold up upon controlling for country specific effects and industry and occupation dummies, as well as industry and occupation interacted with gender. The basic effects I am reporting are thus not an artifact of the sectoral composition of employment. ${ }^{17}$

To assess the magnitude of these interaction effects, it is useful to compare the impact of age, cognitive ability, gender and immigrant status on permanent employment in a country with a low level of employment protection like the United States and one with a high level of protection such as the Netherlands. The difference in the OECD's employment protection index between these two countries is 2.9. Table 6 shows the impact of changing employment protection by this extent on age, gender, cognitive ability and nativity-based gaps in permanent employment, using the logit estimates with country dummies and industry and occupation controls from Table 5. In addition, Table 6 shows the actual incidence of permanent

\footnotetext{
16 The implied partial derivatives for the probability of a permanent job given that one is employed, based on the multinomial logit models of Table 3 were very similar to those based on the logits in Table 5 .

${ }^{17}$ I also tested a series of EPL-demographic interactions with employment in agriculture and employment in manufacturing (included in the logits simultaneously). These models were estimated based on the notion that temporary employment may be especially common in farming and that manufacturing may be a sector with particularly strong protections for insiders. There was a significant positive interaction with education for permanent employment in agriculture and a significant negative interaction with low test score in manufacturing. In each of these cases, protection had a disproportionately positive effect leading to permanent work for skilled workers. The age interactions were also positive in each sector, although they were not significant individually; however, for manufacturing, they were significant as a group. These age point estimates indicated that in agriculture and manufacturing, protection had a disproportionately large effect leading young workers to have a high incidence of temporary work.
} 
employment across these dimensions for the Netherlands and the United States. In order to gauge the importance of employment protection, one can compare the effect of the Dutch-US difference in employment protection on these gaps in permanent employment with the actual Dutch-US difference in the permanent employment gaps.

Beginning with the effect of age, Table 6 shows that among those with wage and salary jobs, only $67.6 \%$ of $16-25$ year olds in the Netherlands have permanent jobs, compared to $81.1 \%$ in the US. Among the more prime age 46-55 year old group, the difference in permanent employment incidence is much smaller: $95.7 \%$ of this group in the Netherlands have a permanent job, while $96.2 \%$ of employed $46-55$ year olds in the US have one. Thus, the actual age gap in permanent employment in the Netherlands is fully 28.1 percentage points, compared to only 15.2 percentage points in the US, for an Italy-US difference of 12.9 percentage points. Table 5's logit estimate for the model with country dummies and industry-occupation controls implies that raising the employment protection mandate from the US to the Dutch level raises the permanent employment gap between 46-55 year olds and 16-25 year olds by 12.6 percentage points, a highly significant effect with an asymptotic standard error of 3.2 percentage points. Table 6 shows that this point estimate is fully $97.5 \%$ of the actual Dutch-US difference in the permanent employment gap between these two age groups. The other logit models yield predicted changes in this gap of 8.5 to 11.6 percentage points, and the OLS results are uniformly larger than any of the logit results. Using any of these parameter estimates, one can conclude that employment protection is an important cause of the fact that young people in the Netherlands have a much lower relative incidence of permanent employment than young people in the US.

Table 6 shows similar results for the degree to which employment protection explains Dutch-US differences in the gender gap, cognitive ability gap, and immigrant-native gap in the incidence of permanent employment. Specifically, men in each country have a higher incidence of permanent employment than women do, and the gender gap is 4.1 percentage points higher in the Netherlands (with rounding). Changing employment protection mandates from the US to the 
Dutch level raises the gender gap in permanent employment by 2.9 percentage points, again a highly significant effect that is more than nine times its asymptotic standard error. The impact accounts for $71 \%$ of the actual Dutch-US difference in the gender gap using the fully specified logit model in Table 5. All of the other models in Table 5 show larger effects than this. Table 6 shows that in the Netherlands, those with low cognitive ability are less likely than others to have a permanent job, while in the US, they are actually slightly more likely. The skill gap in permanent employment is 4.0 percentage points higher in the Netherlands than in the US, and the employment protection effect is $126 \%$ of this, using the last logit model in Table 5, although in this case the effect is not statistically significant. Again, the other models imply larger effects than this, some of which are statistically significant. Finally, natives are 6.0 percentage points more likely in the Netherlands and 0.3 percentage points less likely in the US than immigrants to have permanent jobs, for a 6.4 percentage point Dutch-US difference in the native-immigrant

gap (with rounding). Using the last logit model in Table 5, I conclude that protection explains $101 \%$ of this difference, an effect that is twice its asymptotic standard error. The other parameter estimates in Table 5 imply a range for this estimate of $68 \%$ to $101 \%$. Decomposition results for the US vs. the Italy, another country in my sample with stringent EPL, were very similar to those in Table 6.

\section{B. Alternative Specifications}

In this section, I explore some more detailed specifications of the basic model in order to examine the roles of collective bargaining, gender, temporary employment protection, and possible sample selection bias. Moreover, I present results where the protection measure is disaggregated into its components as well as exploring the sensitivity of the results to exclusion of countries with very high or very low levels of employment protection or exclusion of young people. 


\section{Collective Bargaining Interactions}

Table 7 shows logit results of models with similar collective bargaining interactions to those used in Tables 4 and A2. ${ }^{18}$ The results are in fact very similar to those shown in Table A2, Panel B, which displayed EPL-collective bargaining interaction effects for the probability of permanent vs. temporary employment among the whole population. In contrast, Table 7 shows these effects among wage and salary workers with controls for sector and sector interacted with gender. This design is potentially useful in the event that a country's level of collective bargaining coverage is affected by its occupational-industrial structure, although as noted earlier, institutions can also affect a country's sectoral composition. In any case, Table 7 shows very strong three way interaction effects for age and nativity status. Specifically, more stringent employment protection on regular jobs raises the age gap and the immigrant-native gap in permanent employment substantially more when collective bargaining coverage is high than when it is low, and these three way interactions are highly statistically significant in all specifications. For example, using the difference between Dutch and US collective bargaining coverage of 0.63 (81\% vs. 18\%) and using the most fully specified model in Table 7 , an increase in employment protection from the US to the Dutch level widens the age 46-55 vs. age 16-25 gap in permanent employment by 34.2 percentage points more with the higher collective bargaining level. The native-immigrant permanent employment gap is widened by 24.7 percentage points more in the high collective bargaining coverage than in the low collective bargaining environment.

In addition, the three way interactions with female are negative, large in magnitude and highly significant when I don't control for sector, as was the case for the whole population (Table A2). However, controlling for sector reduces the female interactions to a very small and insignificant level. Thus, to the extent that EPL and CB Cov interact to shut women out of permanent jobs, these effects occur across industries and occupations but not within them. On

18 OLS results for these and the other specifications were largely similar and are available upon request. 
the other hand, if women's sectoral representation is not affected by these institutions, then the results suggest that EPL and collective bargaining don't have strong interaction effects for women. Finally, the three way interactions involving education and cognitive ability go in opposite directions as was the case for the model for the whole population (Table A2). On the one hand, the positive three way interactions with education imply that protection widens the highly educated-less highly educated permanent employment gap more where there is extensive collective bargaining, as the wage floor argument would suggest; on the other hand, I also obtain positive interactions with low test scores, implying the opposite.

Overall, then, I find that collective bargaining coverage accentuates the employment protection effects that reduce the incidence of permanent jobs for the young and immigrants, with possibly similar effects for women to the extent that sectoral composition is an outcome determined by labor market institutions. These findings can be seen as complementary to earlier work that finds that higher collective bargaining coverage leads to lower employment levels for women and youth (Bertola, Blau and Kahn 2002).

\section{Gender Interactions}

The basic model in Table 5 assumes that employment protection has the same effect on women's relative incidence of permanent employment (i.e., versus comparable men), regardless of their age, cognitive ability, education, or nativity status. However, since women are more likely than men to be recent labor market entrants, as well as constrained by wage floors, one might expect these gender effects of employment protection to be stronger in the lower wage or lower skill groups. Indeed, Table 5 shows that, overall, employment protection lowers women's relative likelihood of permanent employment. Table 8 shows logit models where I allow the effects of employment protection by age, education, cognitive ability, and nativity to vary by gender. The three way interactions involving gender, employment protection and the other 
demographic or skill variables are all insignificant and small in magnitude except for a significant, negative interaction with nativity status. ${ }^{19}$

Looking at the effect of protection on immigrant men and women, we see in Table 8 that protection has small, positive, sometimes significant effects on the relative incidence of permanent employment for male immigrants, but the three way interaction with female is significantly negative. Moreover, the effect of protection on the female immigrant relative incidence (vs. female natives) of permanent employment (i.e. adding the protection-immigrant two way interaction term and the three way protection-female-immigrant term) is large in magnitude, ranging from -0.047 to -0.059 and is always statistically significant at better than the 4.6\% level. When I calculated the average effect of protection on the gap for native-born men vs. native-born women (at the mean values for the age dummies, education, and test score), I continued to find that stricter protection raises this gap; this effect was of the same magnitude as the female interaction effects in Table 5. Moreover, this difference was usually statistically significant. Thus, protection reduces the chances that both native and immigrant women will obtain permanent employment, relative to native men and immigrant men, respectively, with a larger effect for immigrants. The findings in Table 8 suggest that employment protection reduces the incidence of permanent jobs for employed immigrant women, but does not do so for immigrant men. Perhaps immigrant women have especially low skill levels or low levels of labor market experience. ${ }^{20}$ Thus it might not be surprising that employed immigrant women's incidence of permanent jobs would be especially affected by EPL. ${ }^{21}$

\footnotetext{
${ }^{19}$ In addition to being small and individually insignificant, the gender-EPL-age interactions were also insignificant as a group in every case.

${ }^{20}$ I also estimated the multinomial logit models of Table 3 with the same female interactions as in Table 8 . The only significant female interactions for the probability of nonemployment (inferred from the multinomial logit coefficients) were a significantly negative interaction with EPL*years of schooling and a significantly negative interaction with EPL*immigrant. In the former case, EPL* years of schooling had a (puzzling) significantly positive effect for men but a small and insignificant effect for women; in the latter case, EPL raised immigrants' relative probability of joblessness significantly for both men and women but by significantly more for men than women. While the lower skills for immigrant women might lead us to expect a more positive effect of EPL on their joblessness relative to immigrant men, perhaps immigrant women's employment is already low due to labor supply considerations.

${ }^{21}$ I also investigated whether the collective bargaining-protection interaction for immigrants shown in Table 7 was significantly different for male vs. female immigrants. In supplementary collective bargaining-interaction models, I
} 


\section{Temporary Employment Regulation}

The theory outlined earlier suggests that greater protection of temporary employment should have the opposite effects of regular employment protection on employed workers' propensities to be in permanent jobs. While countries differ with respect to their regulation of temporary employment, as noted earlier the OECD's (1999) measures of such regulation are highly correlated with permanent employment protection mandates, with a correlation coefficient of 0.74 . Table 9 shows what happens when I add the temporary employment index and its interactions with age, education, cognitive ability, gender, and immigrant status to the basic model in Table 5. There are rarely any significant effects of temporary employment protection. These occur only in the age 46-55 interactions for three of the four models shown in Table 9, and they go in the wrong direction of raising the relative likelihood that people in this age group will have a permanent job. Moreover, the basic regular employment protection interaction effects hold up in sign but are less statistically significant than in Table 5. Only the negative interactions with female and immigrants hold up in statistical significance. And when I estimated the basic Table 5 models with the permanent employment protection terms replaced by temporary employment regulation, the results were virtually identical to those in Table 5. These findings and those in Table 9 reinforce Booth, Dolado and Frank's (2002) conclusion that the OECD's index of temporary employment protection does not add any information beyond what is contained in its index of permanent employment protection.

\section{Sample Selection Bias}

added a three way gender-protection-immigrant, a three way gender-collective bargaining-immigrant, and a four way collective bargaining-gender-protection-immigrant interaction term. The model was therefore saturated with respect to CB Cov, gender, immigrant status and EPL. In all cases, both the three way collective bargainingprotection-immigrant and the four way collective bargaining-gender-protection-immigrant interaction effects were negative; however, while the three way interaction was sometimes significant, the four way interaction was never significant (the joint hypothesis that both interactions were zero was always rejected). Thus, the collective bargaining-protection interaction was not significantly different for male and female immigrants. 
As discussed earlier, the differing employment to population ratios across the countries in my sample raise the possibility that my basic models interacting employment protection and demographic groups may be influenced by sample selection bias. The IALS data show, for example, that among those who were not self-employed, employment to population ratios were highest for Switzerland among men and the US among women. One method to adjust for sample selection is to build a two equation model of employment and permanent employment along the lines suggested by Heckman (1979). However, the IALS does not contain suitable instruments to credibly identify such a system. Instead, I use a technique that is based on a method devised by Hunt (2002) and also implemented by Blau and Kahn (2005).

To understand this adjustment, consider the samples of men. Their employmentpopulation ratios (where the self-employed are not included in the sample) range from 0.581 in Finland to 0.795 in Switzerland. To create a sample of comparably-selected men in each county, I first estimate logits for men's probability of employment separately by country. The explanatory variables include the age dummies, education and the low test score dummy. For each country with a higher male employment to population ratio than Finland's, among those who are employed, I then drop from the sample those with the lowest predicted probabilities of employment, leaving a sample equal to $58.1 \%$ of the population (i.e., Finland's male employment-population ratio). ${ }^{22}$ I perform a similar analysis for women, for whom IALS data show that Italy is the base country with the lowest female employment to population ratio among the non-self-employed at 0.335 . This procedure yields male and female samples with the same relative likelihood of employment and imposes no a priori assumptions about the market or nonmarket productivity of nonparticipants vs. participants. It is similar in spirit to propensity score matching.

\footnotetext{
22 To illustrate this process, consider Switzerland, in which $79.5 \%$ of the population of men who were not selfemployed had jobs. From the Swiss sample of men with wage and salary jobs, I eliminate the lowest $27 \%$ (i.e. $[(0.795-0.581) /(0.795)])$ of individuals with respect to their estimated probability of employment. I perform an analogous adjustment for the other countries.
} 
Table 10 shows the results for my basic specification, where the sample has been adjusted as described above. The results are qualitatively similar to those in Table 5. First, more stringent employment protection raises the age gap in permanent employment for 36-45 and 4655 year olds relative to 26-35 year olds, although the interaction effects are negative for 26-35 year olds vs. 16-25 year olds and are smaller for 56-65 year olds than for those 36-55 years old. Second, protection disproportionately reduces the permanent employment of those with low cognitive ability, with consistently negative effects that are significant two of four times. Third, protection continues to disproportionately reduce the permanent employment of women, effects that are always highly statistically significant. Finally, the protection effects on immigrants are also negative relative to natives, although the coefficients are not significant. But overall, the pattern of results is very similar to those which did not correct for selection. ${ }^{23}$

\section{Disaggregating the Components of the OECD Protection Index}

The results presented so far are based on the OECD's index of employment protection, which is treated as a continuous variable. Not only does this imply a cardinality to the index itself; it also necessarily imposes the OECD's implicit weights from the components of the index. That is, based on the components, the OECD decides on the overall index value. In this section, I present results from basic models where the components have been disaggegated. This design allows us to determine which policy (if any) is most responsible for the basic findings in Table 5. Moreover, for most of the components, the key policy variable is defined as an actual number of years of benefit or mandatory notice entitlement, allowing for a more natural interpretation of a one unit change than would a variable defined as an index.

Table A3 shows the results of this disaggregation. Specifically, I estimate a separate model for each component, in light of the correlation among the components (which prevents

\footnotetext{
${ }^{23}$ When I included the self-employed in the sample and repeated the correction for selection, the results were very similar, and the multinomial logit results in Tables 3, 4 and A2 were very similar when the self-employed were excluded from the sample.
} 
their simultaneous inclusion). These include i) years of mandated severance pay for a worker dismissed after 20 years; ii) years of mandated compensation in the event of unfair dismissal; iii) years of mandatory notice required for someone laid off with 20 years' seniority; and iv) the OECD's index of procedural inconvenience for firms that wish to dismiss workers. The Table shows models including country dummy variables with occupation, industry and their interactions with gender excluded (Panel A) or included (Panel B). Interaction effects between each policy and the key demographic and skill variables are shown. In each case the effects are similar to the aggregated results shown earlier. More generous severance pay or unfair dismissal compensation, longer mandatory notice, and more procedural inconvenience each have positive interaction effects with age and negative interaction effects for those with low test scores, women and immigrants in models estimating the probability of having a permanent job. While the statistical significance of these interaction effects varies, the overall pattern confirms the results based on the OECD's overall index. In particular, the interactions for prime age vs. youth, female vs. male, and immigrant vs. native are usually statistically significant.

\section{Results Excluding Countries with High or Low Employment Protection Levels}

Much has been written about the extensive set of employment protection regulations in Italy (see, for example, Nicoletti 2002). With my relatively small sample of countries, it is possible that the results presented so far reflect Italy-other country differences in the demographic and skill patterns of permanent employment rather than the impact of employment protection. I have therefore estimated the basic permanent employment logit models among wage and salary workers with Italy excluded, and the results are shown in Table A4. The findings are quite similar to those in Table 5. In addition, as Table 1 shows, the Netherlands also has a high OECD overall index rating for employment protection which is actually slightly higher than Italy's. The basic results were similar when the Netherlands was excluded and when both the Netherlands and Italy were excluded from the analysis. Finally, the essential patterns 
remained when the United States, the country with the weakest set of employment protection mandates, was excluded. These alternative analyses excluding key countries imply that the effects I have found in this paper are more general than merely country-specific effects.

\section{Results Excluding Those Age 16-25}

As noted earlier, the quality and availability of schooling opportunities can affect the relative incidence of temporary employment of employed young people. For example, if one is planning to go to school, one may be much more willing than otherwise to take a temporary job. If employment protection laws are correlated with schooling opportunities, then even with country dummies, the positive interaction effects found above for employment protection-age interactions may reflect schooling opportunities. Therefore, to take account of this possibility, I have re-estimated the basic models by excluding those age 16-25. In this way, I focus on a group (those age 26-65) whose choice of permanent or temporary jobs is relatively unaffected by schooling opportunities. Table A5 shows the results of this analysis, and they are very similar to those for the full sample (Table 5). In particular, the age-employment protection effects are all positive and significant (relative to the omitted group, which is $26-35$ year olds) and increase with age. And the interaction effects of protection with low test score, female, and immigrant dummy variables remain negative in every case, and are significant (at the $10 \%$ level on two tailed tests) at least half of the time. Thus, the basic results hold up for a sample which is largely beyond the school-attendance years. ${ }^{24}$

\section{Conclusions}

\footnotetext{
${ }^{24}$ In particular, only about $1 \%$ of those age $26-65$ in the IALS reported school attendance as their major activity, compared to $36 \%$ of $16-25$ year olds.
} 
In this paper, I have estimated the impact of employment protection legislation on the incidence of nonemployment and permanent employment. I argued on theoretical grounds that protection should tend to lower the relative incidence of employment and of permanent jobs for the young, women, immigrants, and the less skilled. I tested these predictions using 1994-98 IALS data on Canada, Finland, Italy, the Netherlands, Switzerland, the United Kingdom, and the United States, countries with widely varying degrees of employment protection. I indeed found that greater protection disproportionately lowered the probability that youths, women, and immigrants were employed; in addition, among those with jobs, I generally found that greater employment protection also lowered the relative incidence of permanent work among these groups, as well as those with low cognitive ability. Upon closer examination, the negative immigrant effects on permanent employment were concentrated on women. Moreover, greater coverage by collective bargaining, with its wage floors, accentuated the effects of employment protection in reducing the incidence of employment for young people and the less skilled; and among the employed, collective bargaining accentuated the negative effects of EPL on the incidence of permanent jobs for the young, those with low cognitive ability, women and immigrants.

My findings are complementary with earlier research which finds that the high wage floors associated with high levels of centralized collective bargaining lead to lower relative employment or higher relative unemployment of young people and women (Kahn 2000; Bertola, Blau and Kahn 2002). Institutions such as collective bargaining and systems of employment protection together have the effect of protecting the permanent jobs of prime age men, at the expense of a possibly large set of outsiders who spend considerable time out of work or shifting among temporary jobs. 


\section{References}

Autor, David H., "Outsourcing at Will: The Contribution of Unjust Dismissal Doctrine to the Growth of Employment Outsourcing," Journal of Labor Economics 12, no. 1 (January 2003): $1-42$.

Autor, David H., John J. Donohue III, and Stewart J. Schwab, “The Costs of WrongfulDischarge Laws," Working Paper, September 2004.

Bertola, Giuseppe, "Job Security, Employment and Wages," European Economic Review 34, no. 4 (June 1990): 851-879.

Bertola, Giuseppe, "Labor Turnover Costs and Average Labor Demand," Journal of Labor Economics 10, no. 4 (October 1992): 389-411.

Bertola, Giuseppe, Francine D. Blau and Lawrence M. Kahn, "Labor Market Institutions and Demographic Employment Patterns," National Bureau of Economic Research Working paper 9043, July 2002.

Blanchard, Olivier and Augustin Landier, "The Perverse Effects of Partial Labour Market Reform: Fixed-Term Contracts in France," Economic Journal 112, no. 480 (June 2002): F214-F244.

Blanchard, Olivier J. and Justin Wolfers, "The Role of Shocks and Institutions in the Rise of European Unemployment: The Aggregate Evidence,” Economic Journal 110, No. 462 (March 2000): C1-C33.

Blau, Francine D. and Lawrence M. Kahn, "International Differences in Male Wage Inequality: Institutions Versus Market Forces," Journal of Political Economy 104, No. 4 (August 1996): 791-837.

Blau, Francine D. and Lawrence M. Kahn, "Do Cognitive Test Scores Explain Higher U.S. Wage Inequality?" The Review of Economics and Statistics 87, no. 1 (February 2005): 184-193.

Booth, Alison L., Juan J. Dolado and Jeff Frank, "Symposium on Temporary Work Introduction,” Economic Journal 112, no. 480 (June 2002): F181-F188.

Booth, Alison L., Marco Francesconi and Jeff Frank, "Temporary Jobs: Stepping Stones or Dead Ends,” Economic Journal 112, no. 480 (June 2002): F189-F213.

Cahuc, Pierre and Postel-Vinay, Fabien, "Temporary Jobs, Employment Protection and Labor Market Performance," Labour Economics 9, no. 1 (February 2002): 63-91.

Dolado, Juan J., Carlos Garcia-Serano and Juan F. Jimeno, "Drawing Lessons from the Boom of Temporary Jobs in Spain,” Economic Journal 112, no. 480 (June 2002): F270-F295.

Güell, Maia, "Fixed-term Contracts and Unemployment: an Efficiency Wage Analysis," Working paper, Universitat Pompeu Fabra, July 2003.

Heckman, James J., "Sample Selection Bias as a Specification Error,” Econometrica 47, no. 1 (January 1979): 153-162. 
Holmlund, Bertil and Donald Storrie, "Temporary Work in Turbulent Times: The Swedish Experience," Economic Journal 112, no. 480 (June 2002): F245-F269.

Hunt, Jennifer, "The Transition in East Germany: When is a Ten Point Fall in the Gender Wage Gap Bad News?" Journal of Labor Economics 20, no. 1 (January 2002): 148-169.

Kahn, Lawrence M., "Wage Inequality, Collective Bargaining and Relative Employment from 1985 to 1994: Evidence from Fifteen OECD Countries," The Review of Economics and Statistics 82, no. 4 (November 2000): 564-579.

Lazear, Edward P., "Job Security Provisions and Employment," Quarterly Journal of Economics 105, no. 3 (August 1990): 699-726.

Nickell, Stephen and Richard Layard, "Labor Market Institutions and Economic Performance," in O. Ashenfelter and D. Card (eds.), Handbook of Labor Economics Volume 3C (Amsterdam: North-Holland, 1999), pp. 3029-3084.

Nickell, Stephen, Luca Nunziata and Wolfgang Ochel, "Unemployment in the OECD Since the 1960s. What Do We Know?” Economic Journal 115, no. 500 (January 2005): 1-27.

Nicoletti, Giuseppe, "Institutions, Economic Structure, and Performance: Is Italy Doomed?" in Institute for Studies and Economic Analyses (ISAE), in ISAE Annual Report on Monitoring Italy, Chapter 3 (Rome: ISAE, 2002), pp. 129-189.

OECD, Employment Outlook: July 1997 (Paris: OECD, 1997).

OECD, Human Capital Investment: An International Comparison (Paris: OECD, 1998).

OECD, Employment Outlook: June 1999 (Paris: OECD, 1999).

OECD, Employment Outlook: July 2002 (Paris: OECD, 2002).

Petrongolo, Barbara, "Gender Segregation in Employment Contracts," Journal of European Economic Association 2, nos. 2-3 (April-May 2004): 331-345.

Rubin Donald B., Multiple Imputation for Nonresponse in Surveys (New York: John Wiley and Sons, 1987).

U.S. Department of Education, National Center for Education Statistics (USDOE, NCES), Adult Literacy in OECD Countries: Technical Report on the First International Adult Literacy Survey, NCES 98-053 (Washington, DC: NCES, 1998). 3029-3084. 


\section{Appendix: IALS Test Scores and the Definition of Low Test Scores (termed “Level 1")}

The IALS gave each respondents tests to measure three kinds of literacy:

“a) Prose literacy — the knowledge and skills needed to understand and use information from texts including editorials, news stories, poems and fiction;

b) Document literacy - the knowledge and skills required to locate and use information contained in various formats, including job applications, payroll forms, transportation schedules, maps, tables, and graphics; and

c) Quantitative literacy — the knowledge and skills required to apply arithmetic operations, either alone or sequentially, to numbers embedded in printed materials, such as balancing a checkbook, calculating a tip, completing an order form, or determining the amount of interest on a loan from an advertisement" (IALS Guide CD-ROM, page 9).

Proficiency in each of the three test areas was scored on a scale of 0-500, after the tests were read by several graders from the respondent's own country. The IALS provides five alternative estimates of proficiency for each test, which were computed from the raw test performance information using a multiple imputation procedure developed by Rubin (1987). These alternative estimates are in fact highly correlated. Within each of the three types of test, the five estimates of the score were correlated at roughly .9. Further, to ensure comparability of grading across countries, an average of $9.4 \%$ of the tests for each country were regraded by personnel from another country; inter-rater agreement with respect to these regrades was $94-99 \%$.

The IALS distinguished five literacy levels based on where one's continuous score fell: Level 1 (0-225); Level 2 (226-275); Level 3 (276-325); Level 4 (326-375); and Level 5 (376-500). In Figure 4 , low test scores are defined as Level 1. For example, on the Prose Literacy test, Level 1 questions require "the reader to locate one piece of information in the text that is identical to or synonymous with the information given in the directive" (IALS Guide CD, page 19). An example, given by the IALS, is to determine from an aspirin bottle label the maximum number of days one should use the product. For higher levels of Prose Literacy, respondents are required to read and interpret more and more dense selections of text and to integrate several pieces of information. On the Document Literacy Test, respondents at Level 1 must "locate a single piece of information based on a literal match" (IALS Guide CD, page 24). Higher Levels of Document Literacy require one to wade through distracting information and to integrate several pieces of information or to make conditional inferences. Finally, the Level 1 Quantitative Literacy questions require the reader to perform a simple calculation that is clearly laid out. Higher Levels of Quantitative Literacy require one to find information given in an example and to know which calculations to make. Comparing those with low cognitive ability with others is a particularly relevant exercise here. This is the case, since wage floors (and therefore constraints on firms' ability to compensate for high firing costs by lowering wages) are most likely to be binding for those with low ability (as well as other low wage workers such as youth, immigrants and women). 
Figure 1: Incidence of Permanent Employment by Strength of Permanent Employment Protection, Men and Women

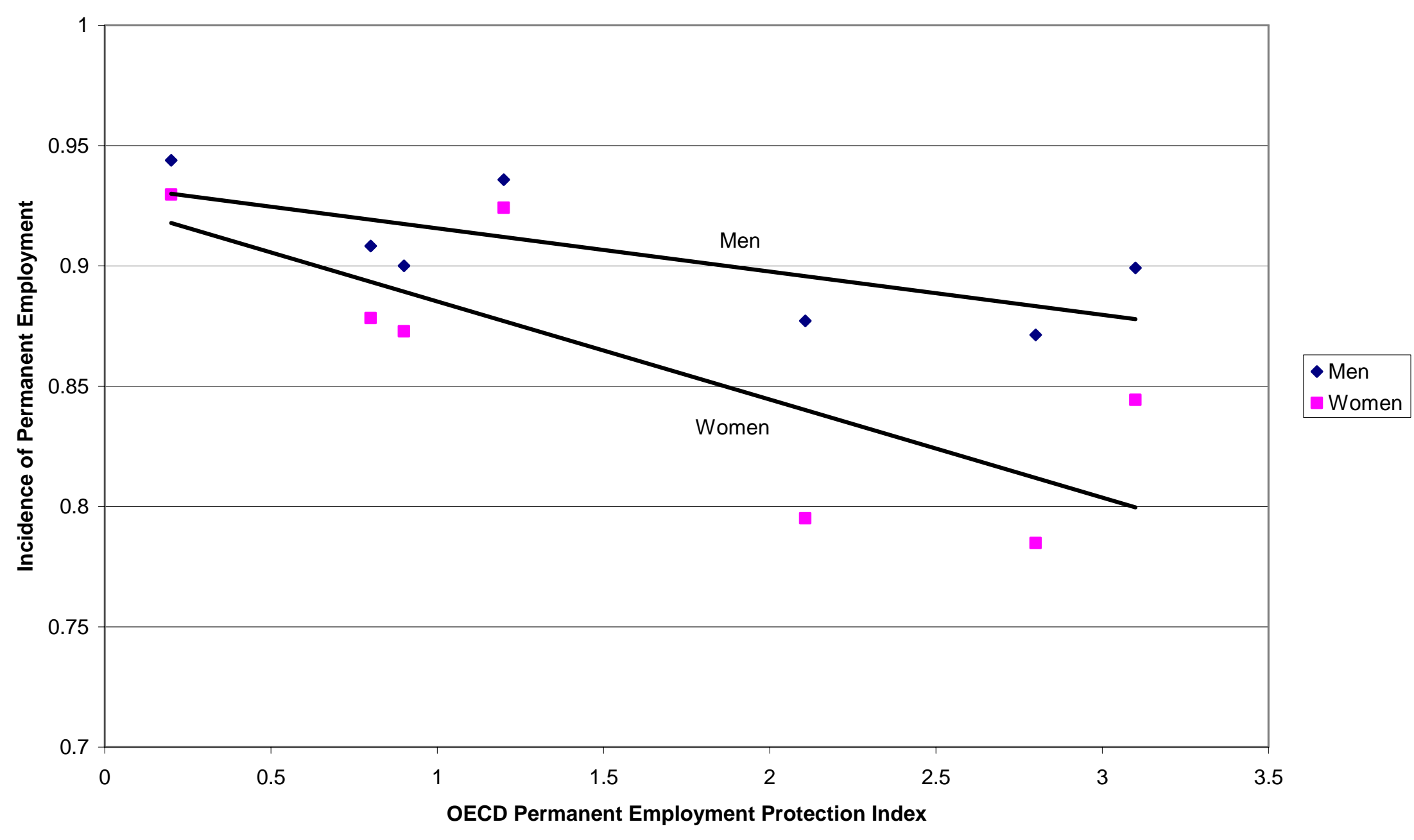


Figure 2: Incidence of Permanent Employment by Strength of Permanent Employment Protection, Age 16-25 and Age 46-55

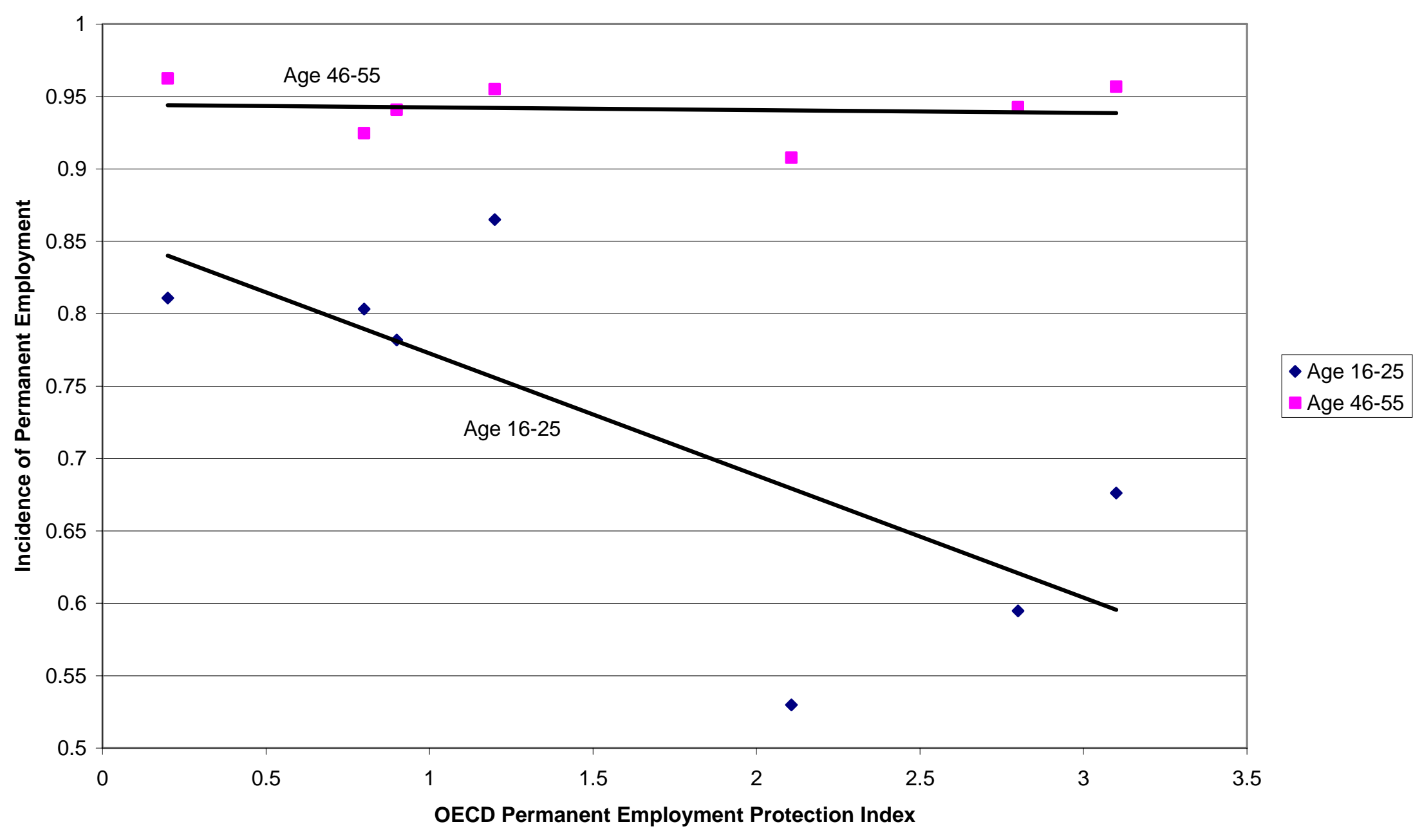


Figure 3: Incidence of Permanent Employment by Strength of Permanent Employment Protection, Natives and Immigrants

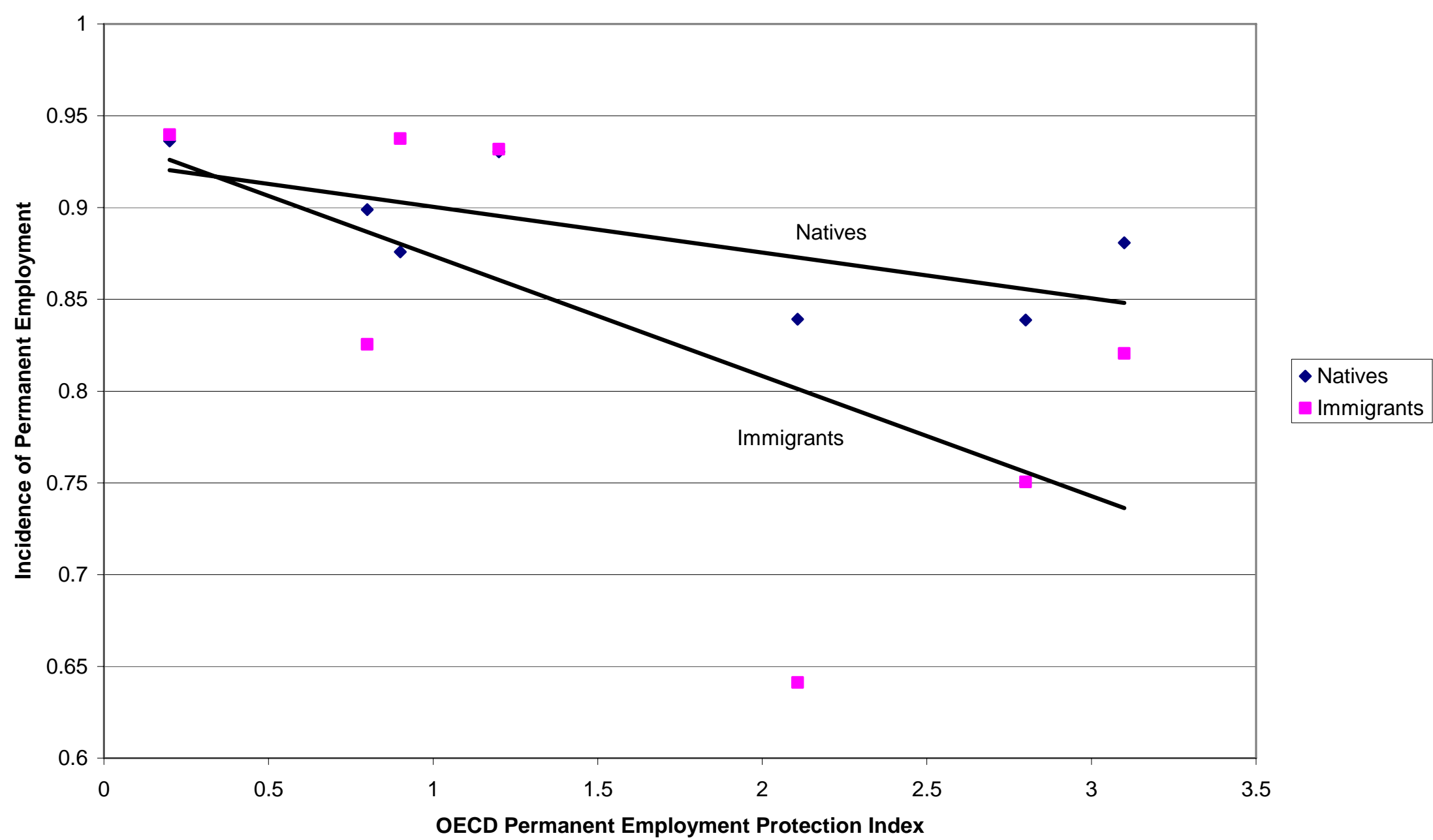


Figure 4: Incidence of Permanent Employment by Strength of Permanent Employment Protection, Individuals with Low Test Scores vs. Others

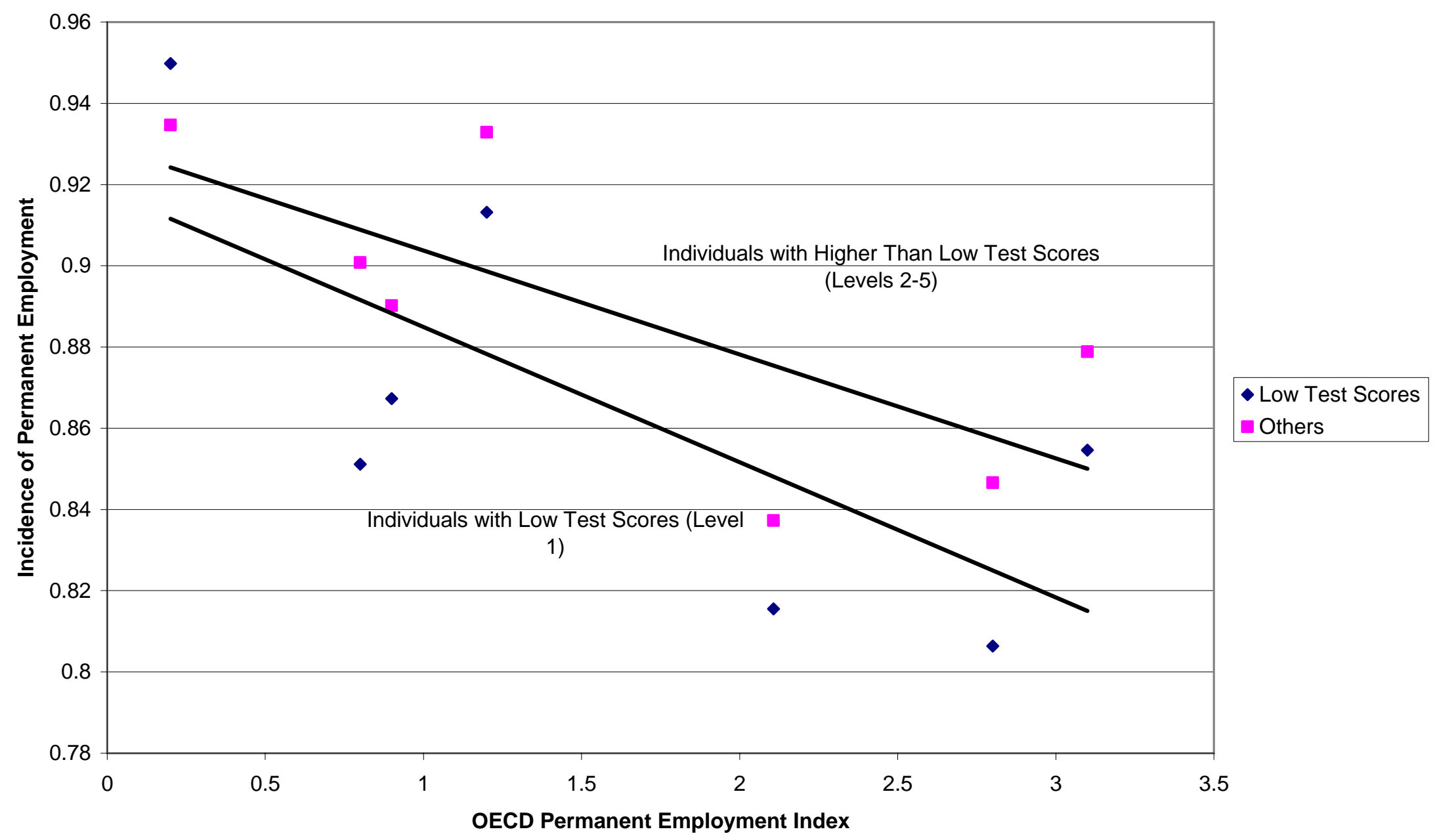


Table 1: Employment Protection Mandates for Regular Employment, Late 1990s

\begin{tabular}{|c|c|c|c|c|}
\hline $\begin{array}{c}\text { onths of Severance Pay for No- } \\
\text { Fault Dismissals by Tenure } \\
\text { Category: }\end{array}$ & $\begin{array}{l}\text { Unfair Dismissal } \\
\text { Compensation, } \\
20 \text { Years Tenure } \\
\text { (months) }\end{array}$ & $\begin{array}{l}\text { Mandatory Notice } \\
\text { for Individual } \\
\text { Dismissals, } 20 \\
\text { Years Tenure } \\
\text { (months) }\end{array}$ & $\begin{array}{c}\text { Index of } \\
\text { Procedural } \\
\text { Inconvenience (0 } \\
\text { to } 6 \text { scale) }\end{array}$ & $\begin{array}{l}\text { Overall Regular } \\
\text { Employment } \\
\text { Protection Score } \\
\text { (0 to } 6 \text { scale) }\end{array}$ \\
\hline
\end{tabular}

9 Months 4 Years 20 Years

\begin{tabular}{|c|c|c|c|c|c|c|c|}
\hline Canada & 0.0 & 0.2 & 1.3 & 0.0 & 0.5 & 0.0 & 0.9 \\
\hline Finland & 0.0 & 0.0 & 0.0 & 12.0 & 6.0 & 2.8 & 2.1 \\
\hline Italy & 0.7 & 3.5 & 18.0 & 32.5 & 2.2 & 1.5 & 2.8 \\
\hline Netherlands & 0.0 & 0.0 & 0.0 & 18.0 & 3.0 & 5.0 & 3.1 \\
\hline Switzerland & 0.0 & 0.0 & 2.0 & 6.0 & 3.0 & 0.5 & 1.2 \\
\hline UK & 0.0 & 0.5 & 2.4 & 8.0 & 2.8 & 1.0 & 0.8 \\
\hline USA & 0.0 & 0.0 & 0.0 & 0.0 & 0.0 & 0.0 & 0.2 \\
\hline
\end{tabular}

Source: OECD (1999), pp. 55 and 66. 
Table 2: Employment Protection Mandates for Temporary Employment, Late 1990s

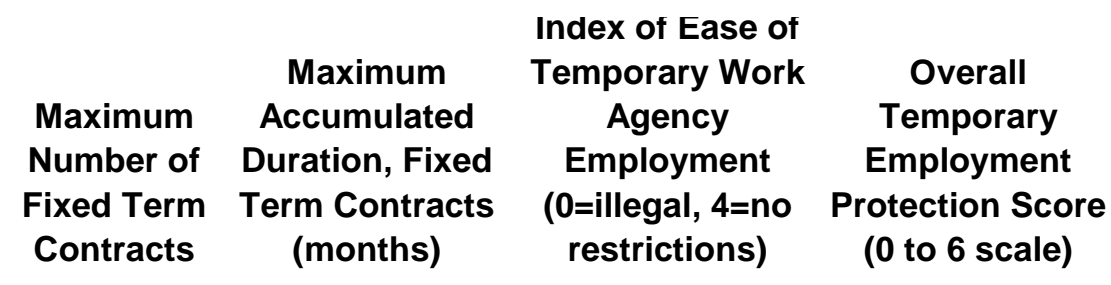

\begin{tabular}{lccll}
\hline Canada & No limit & No limit & 4.0 & 0.3 \\
Finland & 1.5 & No limit & 4.0 & 1.9 \\
Italy & 2.0 & 15.0 & 1.0 & 3.8 \\
Netherlands & 3.0 & No limit & 3.5 & 1.2 \\
Switzerland & 1.5 & No limit & 4.0 & 0.9 \\
UK & No limit & No limit & 4.0 & 0.3 \\
USA & No limit & No limit & 4.0 & 0.3 \\
\hline
\end{tabular}

Source: OECD (1999), pp. 62 and 66. 
Table 3: Selected Multinomial Logit Results for the Effects of Employment Protection (EPL Index) on Nonemployment, Temporary Employment and Permanent Employment (sample includes all adults)

\begin{tabular}{|c|c|c|c|c|c|c|}
\hline A. Probability of Permanent & & & & & & \\
\hline $\begin{array}{l}\text { Employment vs. Nonemployment } \\
\text { (multinomial logit coeffs) }\end{array}$ & coef & ase & $\begin{array}{l}\text { relative } \\
\text { risk ratio }\end{array}$ & coef & ase & $\begin{array}{l}\text { relative } \\
\text { risk ratio }\end{array}$ \\
\hline EPL Index & -0.159 & 0.232 & 0.853 & --- & --- & --- \\
\hline EPL Index*Age 26-35 & 0.319 & 0.203 & 1.376 & 0.309 & 0.199 & 1.362 \\
\hline EPL Index*Age 36-45 & 0.366 & 0.250 & 1.441 & 0.360 & 0.247 & 1.433 \\
\hline EPL Index*Age 46-55 & 0.257 & 0.263 & 1.293 & 0.253 & 0.262 & 1.287 \\
\hline EPL Index*Age 56-65 & 0.046 & 0.236 & 1.047 & 0.052 & 0.233 & 1.053 \\
\hline EPL Index*Education & -0.019 & 0.012 & 0.981 & -0.019 & 0.010 & 0.982 \\
\hline EPL Index*Low Test Score & 0.047 & 0.053 & 1.048 & 0.059 & 0.050 & 1.061 \\
\hline EPL Index*Female & -0.149 & 0.090 & 0.862 & -0.140 & 0.091 & 0.870 \\
\hline EPL Index*Immigrant & -0.300 & 0.077 & 0.741 & -0.336 & 0.060 & 0.714 \\
\hline Country dummies? & & no & & & yes & \\
\hline Sample size & & 26159 & & & 26159 & \\
\hline B. Probability of Permanent & & & & & & \\
\hline $\begin{array}{l}\text { Employment vs. Temporary Employment } \\
\text { (multinomial logit coeffs) }\end{array}$ & coef & asy se & $\begin{array}{l}\text { relative } \\
\text { risk ratio }\end{array}$ & coef & asy se & $\begin{array}{l}\text { relative } \\
\text { risk ratio }\end{array}$ \\
\hline EPL Index & -0.231 & 0.269 & 0.794 & --- & --- & --- \\
\hline EPL Index*Age 26-35 & 0.046 & 0.091 & 1.048 & 0.028 & 0.100 & 1.028 \\
\hline EPL Index*Age 36-45 & 0.282 & 0.190 & 1.325 & 0.296 & 0.207 & 1.345 \\
\hline EPL Index*Age 46-55 & 0.373 & 0.135 & 1.453 & 0.405 & 0.145 & 1.499 \\
\hline EPL Index*Age 56-65 & 0.719 & 0.231 & 2.053 & 0.825 & 0.246 & 2.282 \\
\hline EPL Index*Education & -0.004 & 0.019 & 0.996 & -0.001 & 0.019 & 0.999 \\
\hline EPL Index*Low Test Score & -0.201 & 0.097 & 0.818 & -0.200 & 0.105 & 0.819 \\
\hline EPL Index*Female & -0.159 & 0.043 & 0.853 & -0.150 & 0.048 & 0.861 \\
\hline EPL Index*Immigrant & -0.225 & 0.125 & 0.798 & -0.258 & 0.149 & 0.773 \\
\hline Country dummies? & & no & & & yes & \\
\hline Sample size & & 26159 & & & 26159 & \\
\hline
\end{tabular}


Table 3 (ctd): Selected Multinomial Logit Results for the Effects of Employment Protection (EPL Index) on Nonemployment, Temporary Employment and Permanent Employment (sample includes all adults)

\begin{tabular}{|c|c|c|c|c|}
\hline $\begin{array}{l}\text { C. Derivative of Prob of Nonemployment (at } \\
\text { mean frequencies of employment outcomes) }\end{array}$ & coef & ase & coef & ase \\
\hline EPL Index & 0.031 & 0.050 & --- & --- \\
\hline EPL Index*Age 26-35 & -0.072 & 0.046 & -0.070 & 0.046 \\
\hline EPL Index*Age 36-45 & -0.077 & 0.057 & -0.076 & 0.057 \\
\hline EPL Index*Age 46-55 & -0.050 & 0.060 & -0.048 & 0.060 \\
\hline EPL Index*Age 56-65 & 0.007 & 0.054 & 0.008 & 0.054 \\
\hline EPL Index*Education & 0.004 & 0.003 & 0.004 & 0.002 \\
\hline EPL Index*Low Test Score & -0.016 & 0.011 & -0.019 & 0.010 \\
\hline EPL Index*Female & 0.030 & 0.020 & 0.029 & 0.020 \\
\hline EPL Index*Immigrant & 0.064 & 0.018 & 0.071 & 0.015 \\
\hline Country dummies? & \multicolumn{2}{|c|}{ no } & \multicolumn{2}{|c|}{ yes } \\
\hline Sample size & \multicolumn{2}{|c|}{26159} & \multicolumn{2}{|c|}{26159} \\
\hline \multirow{2}{*}{\multicolumn{5}{|c|}{$\begin{array}{l}\text { D. Derivative of Prob of Permanent } \\
\text { Employment (at mean frequencies of } \\
\text { emplovment outcomes) }\end{array}$}} \\
\hline & & & & \\
\hline EPL Index & -0.042 & 0.055 & --- & --- \\
\hline EPL Index*Age 26-35 & 0.068 & 0.043 & 0.065 & 0.042 \\
\hline EPL Index*Age 36-45 & 0.086 & 0.052 & 0.086 & 0.052 \\
\hline EPL Index*Age 46-55 & 0.067 & 0.056 & 0.068 & 0.055 \\
\hline EPL Index*Age 56-65 & 0.037 & 0.050 & 0.042 & 0.049 \\
\hline EPL Index ${ }^{\star}$ Education & -0.004 & 0.003 & -0.004 & 0.002 \\
\hline EPL Index*Low Test Score & 0.002 & 0.013 & 0.005 & 0.013 \\
\hline EPL Index*Female & -0.037 & 0.019 & -0.035 & 0.020 \\
\hline EPL Index*Immigrant & -0.071 & 0.017 & -0.079 & 0.013 \\
\hline Country dummies? & no & & yes & \\
\hline Sample size & 26159 & & 26159 & \\
\hline
\end{tabular}

EPL Index is the OECD's index of strength of employment protection mandates for regular jobs. Controls include age dummies, education, low test score dummy, immigrant dummy and a female dummy and female interactions with each of these variables. (Asymptotic) standard errors corrected for correlation within countries. Data are weighted using IALS sampling weights adjusted so that each country gets the same total weight. Relative risk ratio equals $\exp$ (multinomial logit coefficient). 
Table 4: Selected Multinomial Logit Results for the Interaction Effects of Employment Protection (EPL Index) and Collective Bargaining coverage (CB Cov) on Nonemployment, Temporary Employment and Permanent Employment (sample includes all adults)

\begin{tabular}{|c|c|c|c|c|}
\hline $\begin{array}{l}\text { A. Derivative of Prob of Nonemployment (at mean } \\
\text { frequencies of employment outcomes) }\end{array}$ & effect & ase & effect & ase \\
\hline EPL Index*Age $26-35^{\star}$ CB Cov & -0.231 & 0.143 & -0.234 & 0.142 \\
\hline EPL Index*Age $36-45^{\star}$ CB Cov & -0.243 & 0.102 & -0.234 & 0.106 \\
\hline EPL Index*Age $46-55^{\star}$ CB Cov & -0.235 & 0.119 & -0.242 & 0.117 \\
\hline EPL Index*Age 56-65*CB Cov & -0.025 & 0.145 & -0.045 & 0.150 \\
\hline EPL Index*Education*CB Cov & -0.042 & 0.024 & -0.036 & 0.023 \\
\hline EPL Index*Low Test Score*CB Cov & 0.085 & 0.062 & 0.136 & 0.071 \\
\hline EPL Index*Female*CB Cov & -0.055 & 0.102 & -0.053 & 0.105 \\
\hline EPL Index*Immigrant*CB Cov & -0.043 & 0.092 & -0.014 & 0.060 \\
\hline Country dummies? & \multirow{2}{*}{\multicolumn{2}{|c|}{$\begin{array}{c}\text { no } \\
26159\end{array}$}} & \multirow{2}{*}{\multicolumn{2}{|c|}{$\begin{array}{c}\text { yes } \\
26159\end{array}$}} \\
\hline Sample size & & & & \\
\hline $\begin{array}{l}\text { B. Derivative of Prob of Permanent Employment (at } \\
\text { mean frequencies of employment outcomes) }\end{array}$ & effect & ase & effect & ase \\
\hline EPL Index*Age $26-35^{\star}$ CB Cov & 0.290 & 0.128 & 0.307 & 0.125 \\
\hline EPL Index*Age $36-45^{\star}$ CB Cov & 0.421 & 0.095 & 0.428 & 0.096 \\
\hline EPL Index*Age $46-55^{\star}$ CB Cov & 0.346 & 0.112 & 0.362 & 0.108 \\
\hline EPL Index*Age 56-65*CB Cov & 0.168 & 0.138 & 0.194 & 0.138 \\
\hline EPL Index*Education*CB Cov & 0.044 & 0.021 & 0.038 & 0.020 \\
\hline EPL Index*Low Test Score*CB Cov & 0.028 & 0.055 & -0.029 & 0.064 \\
\hline EPL Index*Female*CB Cov & 0.002 & 0.093 & -0.007 & 0.094 \\
\hline EPL Index*Immigrant*CB Cov & -0.040 & 0.084 & -0.067 & 0.059 \\
\hline Country dummies? & no & & yes & \\
\hline Sample size & 26159 & & 26159 & \\
\hline
\end{tabular}

EPL Index is the OECD's index of strength of employment protection for regular jobs, and CB Cov is collective bargaining coverage. Entries are partial derivatives of unconditional probabilities based on multinomial logit models with nonemployment, temporary employment and permanent employment as possible outcomes. Controls include age dummies, education, low test score dummy, immigrant dummy and a female dummy and female interactions with each of these variables, and interactions between $\mathrm{cb}$ and each of these controls; in addition, EPL interactions with age dummies, education, low test score, female and immigrant are included. In models excluding country dummies, EPL, CB Cov and EPL ${ }^{\star} C B$ Cov are included. Asymptotic standard errors are corrected for correlation within countries. Data are weighted using IALS sampling weights adjusted so that each country gets the same total weight. 
Table 5: Selected Regression Results for the Effects of Employment Protection (EPL Index) on Permanent Employment (sample includes only employed wage and salary workers)

\begin{tabular}{|c|c|c|c|c|c|c|c|c|}
\hline A. Ordinary Least Squares & coef & se & coef & se & coef & se & coef & se \\
\hline EPL Index & -0.045 & 0.030 & -0.039 & 0.027 & --- & --- & --- & --- \\
\hline EPL Index*Age 26-35 & 0.031 & 0.009 & 0.030 & 0.008 & 0.035 & 0.010 & 0.033 & 0.009 \\
\hline EPL Index*Age 36-45 & 0.058 & 0.017 & 0.058 & 0.017 & 0.063 & 0.018 & 0.063 & 0.018 \\
\hline EPL Index*Age 46-55 & 0.067 & 0.017 & 0.067 & 0.017 & 0.074 & 0.019 & 0.074 & 0.019 \\
\hline EPL Index*Age 56-65 & 0.080 & 0.021 & 0.079 & 0.021 & 0.087 & 0.023 & 0.086 & 0.023 \\
\hline EPL Index*Education & -0.001 & 0.002 & -0.002 & 0.002 & -0.001 & 0.002 & -0.002 & 0.002 \\
\hline EPL Index*Low Test Score & -0.029 & 0.011 & -0.026 & 0.012 & -0.024 & 0.014 & -0.022 & 0.014 \\
\hline EPL Index*Female & -0.020 & 0.008 & -0.019 & 0.007 & -0.016 & 0.007 & -0.016 & 0.006 \\
\hline EPL Index*Immigrant & -0.016 & 0.010 & -0.017 & 0.010 & -0.025 & 0.009 & -0.025 & 0.009 \\
\hline occup, ind? & \multicolumn{2}{|c|}{ no } & \multicolumn{2}{|c|}{ yes } & \multicolumn{2}{|c|}{ no } & \multicolumn{2}{|c|}{ yes } \\
\hline (occup,ind) ${ }^{\star}$ female interactions? & \multicolumn{2}{|c|}{ no } & \multicolumn{2}{|c|}{ yes } & \multicolumn{2}{|c|}{ no } & \multicolumn{2}{|c|}{ yes } \\
\hline Country dummies? & \multicolumn{2}{|c|}{ no } & \multicolumn{2}{|c|}{ no } & \multicolumn{2}{|c|}{ yes } & \multicolumn{2}{|c|}{ yes } \\
\hline Sample size & \multicolumn{2}{|c|}{13736} & \multicolumn{2}{|c|}{13736} & \multicolumn{2}{|c|}{13736} & \multicolumn{2}{|c|}{13736} \\
\hline $\begin{array}{l}\text { B. Logit (partial derivatives at } \\
\text { mean of dependent variable) }\end{array}$ & coef & asy se & coef & asy se & coef & asy se & coef & asy se \\
\hline EPL Index & -0.019 & 0.031 & -0.014 & 0.026 & --- & --- & --- & --- \\
\hline EPL Index*Age 26-35 & -0.002 & 0.008 & -0.003 & 0.007 & 0.001 & 0.009 & 0.000 & 0.008 \\
\hline EPL Index*Age 36-45 & 0.021 & 0.015 & 0.023 & 0.013 & 0.029 & 0.017 & 0.032 & 0.016 \\
\hline EPL Index*Age 46-55 & 0.029 & 0.011 & 0.033 & 0.011 & 0.040 & 0.012 & 0.043 & 0.011 \\
\hline EPL Index*Age 56-65 & 0.057 & 0.024 & 0.061 & 0.022 & 0.074 & 0.027 & 0.078 & 0.026 \\
\hline EPL Index*Education & -0.001 & 0.002 & -0.001 & 0.002 & -0.001 & 0.002 & -0.001 & 0.002 \\
\hline EPL Index*Low Test Score & -0.020 & 0.012 & -0.020 & 0.013 & -0.016 & 0.014 & -0.017 & 0.015 \\
\hline EPL Index*Female & -0.013 & 0.003 & -0.012 & 0.001 & -0.011 & 0.002 & -0.010 & 0.001 \\
\hline EPL Index*Immigrant & -0.015 & 0.010 & -0.016 & 0.010 & -0.022 & 0.012 & -0.022 & 0.011 \\
\hline occup, ind? & \multicolumn{2}{|c|}{ no } & \multicolumn{2}{|c|}{ yes } & \multicolumn{2}{|c|}{ no } & \multicolumn{2}{|c|}{ yes } \\
\hline (occup,ind) ${ }^{\star}$ female interactions? & \multicolumn{2}{|c|}{ no } & \multicolumn{2}{|c|}{ yes } & \multicolumn{2}{|c|}{ no } & \multicolumn{2}{|c|}{ yes } \\
\hline Country dummies? & \multicolumn{2}{|c|}{ no } & \multicolumn{2}{|c|}{ no } & \multicolumn{2}{|c|}{ yes } & \multicolumn{2}{|c|}{ yes } \\
\hline Sample size & \multicolumn{2}{|c|}{13736} & \multicolumn{2}{|c|}{13736} & & & & \\
\hline
\end{tabular}

EPL Index is the OECD's index of strength of employment protection mandates for regular jobs.

Controls include age dummies, education, low test score dummy, immigrant dummy and a female dummy and female interactions with each of these variables. (Asymptotic) standard errors corrected for correlation within countries. Data are weighted using IALS sampling weights adjusted so that each country gets the same total weight. 
Table 6: Effect of Employment Protection on US-Netherlands Differences in Age, Gender, Immigrant Status, and Cognitive Ability-Based Gaps in Permanent Employment Incidence (among wage and salary workers)

Dimension

1. Age

46-55 Permanent Employment Incidence

16-25 Permanent Employment Incidence

Actual Permanent Employment Gap (46-55 minus 16-25)

Effect of Changing from US to Dutch Protection

Percentage of US-Dutch Difference Explained by Protection

2. Gender

Male Permanent Employment Incidence

Female Permanent Employment Incidence

Actual Permanent Employment Gap (Male minus Female)

Effect of Changing from US to Dutch Protection

Percentage of US-Dutch Difference Explained by Protection

3. Cognitive Ability

Permanent Employment Incidence for Higher Than Level 1 Test Score Permanent Employment Incidence for Low Test Score (Level 1)

Actual Permanent Employment Gap (Above Level 1 minus Level 1)

Effect of Changing from US to Dutch Protection

Percentage of US-Dutch Difference Explained by Protection

4. Nativity

Native Permanent Employment Incidence

Immigrant Permanent Employment Incidence

Actual Permanent Employment Gap (Native minus Immigrant)

Effect of Changing from US to Dutch Protection

Percentage of US-Dutch Difference Explained by Protection
Netherlands

US

Difference: Netherlands-US

Effect

Asy std err

0.957

0.676

0.281

0.962

0.811

0.152

$----$

----

$---$

$-0.006$

$-0.135$

0.129

0.126

$----$

0.899

0.844

0.944

0.055

\subsection{0}

0.014

$----$

----

$---$

0.879

0.855

0.024

0.935

0.950

$-0.015$

$----$

$---$

$---$

$97.5 \%$

$-0.045$

$-0.085$

0.041

0.029

$71.0 \%$

$-0.056$

$-0.095$

0.040

0.050

$126.2 \%$

0.043

$109.9 \%$

$\begin{array}{cccc}0.881 & 0.936 & -0.055 & ---- \\ 0.821 & 0.940 & -0.119 & ---- \\ 0.060 & -0.003 & 0.064 & ---- \\ ---- & ---- & 0.064 & 0.032 \\ ---- & ---- & 100.8 \% & 50.3 \%\end{array}$

Note: Based on Logit model with country dummies and occupation-industry controls (last model of Table 5, Panel B). 
Table 7: Selected Logit Results for the Effects of Employment Protection (EPL Index) on Permanent Employment, with Collective Bargaining Coverage (CB Cov) Interactions, Wage and Salary Workers (partial derivatives at mean of dependent variable)

\begin{tabular}{|c|c|c|c|c|c|c|c|c|}
\hline & coef & asy se & coef & asy se & coef & asy se & coef & asy se \\
\hline EPL Index*Age 26-35 & -0.096 & 0.018 & -0.084 & 0.016 & -0.108 & 0.011 & -0.095 & 0.014 \\
\hline EPL Index*Age 36-45 & -0.202 & 0.022 & -0.193 & 0.020 & -0.209 & 0.015 & -0.199 & 0.015 \\
\hline EPL Index*Age 46-55 & -0.097 & 0.024 & -0.088 & 0.023 & -0.103 & 0.018 & -0.092 & 0.019 \\
\hline EPL Index*Age 56-65 & -0.080 & 0.064 & -0.067 & 0.059 & -0.091 & 0.057 & -0.075 & 0.050 \\
\hline EPL Index*Education & -0.005 & 0.003 & -0.004 & 0.003 & -0.005 & 0.003 & -0.003 & 0.003 \\
\hline EPL Index*Low Test Score & -0.108 & 0.025 & -0.102 & 0.019 & -0.101 & 0.024 & -0.098 & 0.020 \\
\hline EPL Index*Female & 0.037 & 0.008 & 0.006 & 0.009 & 0.041 & 0.008 & 0.012 & 0.009 \\
\hline EPL Index*Immigrant & 0.137 & 0.049 & 0.133 & 0.049 & 0.148 & 0.070 & 0.139 & 0.067 \\
\hline CB Cov^Age 26-35 & -0.058 & 0.037 & -0.060 & 0.032 & -0.082 & 0.027 & -0.086 & 0.027 \\
\hline CB Cov^Age 36-45 & -0.134 & 0.047 & -0.105 & 0.037 & -0.169 & 0.030 & -0.144 & 0.017 \\
\hline CB CovAge 46-55 & -0.168 & 0.044 & -0.149 & 0.047 & -0.195 & 0.046 & -0.180 & 0.053 \\
\hline CB CovAge 56-65 & -0.467 & 0.151 & -0.432 & 0.173 & -0.506 & 0.115 & -0.462 & 0.140 \\
\hline CB Cov^Education & -0.060 & 0.008 & -0.056 & 0.007 & -0.057 & 0.007 & -0.053 & 0.007 \\
\hline CB Cov^Low Test Score & -0.338 & 0.049 & -0.337 & 0.052 & -0.363 & 0.046 & -0.356 & 0.053 \\
\hline CB CovFemale & -0.021 & 0.010 & -0.043 & 0.032 & -0.010 & 0.021 & -0.032 & 0.038 \\
\hline CB Cov*Immigrant & -0.137 & 0.130 & -0.109 & 0.128 & -0.171 & 0.157 & -0.140 & 0.147 \\
\hline CB Cov^EPL Index*Age 26-35 & 0.115 & 0.015 & 0.102 & 0.011 & 0.135 & 0.009 & 0.121 & 0.012 \\
\hline CB Cov^EPL Index*Age 36-45 & 0.273 & 0.031 & 0.259 & 0.029 & 0.290 & 0.021 & 0.276 & 0.020 \\
\hline CB Cov^EPL Index^Age 46-55 & 0.185 & 0.030 & 0.173 & 0.028 & 0.200 & 0.023 & 0.187 & 0.023 \\
\hline CB Cov^EPL Index^Age 56-65 & 0.302 & 0.060 & 0.285 & 0.063 & 0.326 & 0.063 & 0.302 & 0.062 \\
\hline CB CovEPL Index*Education & 0.019 & 0.005 & 0.016 & 0.005 & 0.017 & 0.005 & 0.014 & 0.005 \\
\hline CB CovEPL Index*Low Test Score & 0.166 & 0.025 & 0.161 & 0.021 & 0.172 & 0.028 & 0.168 & 0.026 \\
\hline CB Cov^EPL IndexFemale & -0.046 & 0.008 & -0.008 & 0.014 & -0.051 & 0.010 & -0.015 & 0.014 \\
\hline CB Cov*EPL Index*Immigrant & -0.128 & 0.048 & -0.131 & 0.041 & -0.137 & 0.064 & -0.135 & 0.057 \\
\hline occup, ind? & \multicolumn{2}{|c|}{ no } & \multicolumn{2}{|c|}{ yes } & \multicolumn{2}{|c|}{ no } & \multicolumn{2}{|c|}{ yes } \\
\hline (occup,ind) ${ }^{\star}$ female interactions? & \multicolumn{2}{|c|}{ no } & \multicolumn{2}{|c|}{ yes } & \multicolumn{2}{|c|}{ no } & \multicolumn{2}{|c|}{ yes } \\
\hline Country dummies? & \multicolumn{2}{|c|}{ no } & \multicolumn{2}{|c|}{ no } & \multicolumn{2}{|c|}{ yes } & \multicolumn{2}{|c|}{ yes } \\
\hline Sample size & \multicolumn{2}{|c|}{13736} & \multicolumn{2}{|c|}{13736} & \multicolumn{2}{|c|}{13736} & \multicolumn{2}{|c|}{13736} \\
\hline
\end{tabular}

EPL Index is the OECD's index of strength of employment protection mandates for regular jobs. CB Cov is fraction covered by collective bargaining. Controls include age dummies, education, and dummies for low test score, immigrant, and female as well as female interactions with each of these variables. In models excluding country dummies, EPL, CB Cov and $E P L{ }^{*} C B$ Cov are included. (Asymptotic) standard errors are corrected for correlation within countries.

Data are weighted using IALS sampling weights adjusted so that each country gets the same total weight. 
Table 8: Selected Logit Results for the Effects of Employment Protection (EPL Index) on Permanent Employment, with Female Interactions, Wage and Salary Workers (partial derivatives at mean of dependent variable)

\begin{tabular}{|c|c|c|c|c|c|c|c|c|}
\hline & coef & asy se & coef & asy se & coef & asy se & coef & asy se \\
\hline EPL Index & -0.013 & 0.023 & -0.005 & 0.014 & --- & --- & --- & --- \\
\hline EPL Index*Age 26-35 & 0.004 & 0.006 & 0.001 & 0.006 & 0.005 & 0.005 & 0.002 & 0.006 \\
\hline EPL Index*Age 36-45 & 0.026 & 0.022 & 0.031 & 0.020 & 0.033 & 0.025 & 0.038 & 0.022 \\
\hline EPL Index*Age 46-55 & 0.040 & 0.013 & 0.045 & 0.011 & 0.048 & 0.014 & 0.053 & 0.011 \\
\hline EPL Index*Age 56-65 & 0.068 & 0.022 & 0.066 & 0.022 & 0.080 & 0.024 & 0.077 & 0.024 \\
\hline EPL Index*Education & -0.002 & 0.002 & -0.002 & 0.001 & -0.002 & 0.002 & -0.003 & 0.001 \\
\hline EPL Index*Low Test Score & -0.028 & 0.008 & -0.028 & 0.010 & -0.022 & 0.007 & -0.023 & 0.009 \\
\hline EPL Index*Female & -0.024 & 0.052 & -0.031 & 0.049 & -0.028 & 0.056 & -0.033 & 0.052 \\
\hline EPL Index*Immigrant & 0.014 & 0.007 & 0.016 & 0.009 & 0.008 & 0.006 & 0.010 & 0.008 \\
\hline Female*EPL Index*Age 26-35 & -0.011 & 0.019 & -0.007 & 0.018 & -0.008 & 0.021 & -0.004 & 0.020 \\
\hline Female*EPL Index*Age 36-45 & -0.010 & 0.024 & -0.013 & 0.024 & -0.007 & 0.028 & -0.011 & 0.027 \\
\hline Female*EPL Index*Age 46-55 & -0.019 & 0.025 & -0.022 & 0.023 & -0.013 & 0.029 & -0.018 & 0.026 \\
\hline Female*EPL Index*Age 56-65 & -0.019 & 0.032 & -0.008 & 0.035 & -0.010 & 0.040 & 0.002 & 0.043 \\
\hline Female*EPL Index*Education & 0.002 & 0.003 & 0.002 & 0.003 & 0.002 & 0.003 & 0.002 & 0.003 \\
\hline Female*EPL Index*Low Test Score & 0.014 & 0.032 & 0.014 & 0.037 & 0.011 & 0.034 & 0.011 & 0.039 \\
\hline Female*EPL Index*Immigrant & -0.061 & 0.026 & -0.067 & 0.029 & -0.064 & 0.028 & -0.069 & 0.031 \\
\hline occup, ind? & \multicolumn{2}{|c|}{ no } & \multicolumn{2}{|c|}{ yes } & \multicolumn{2}{|c|}{ no } & \multicolumn{2}{|c|}{ yes } \\
\hline (occup,ind)^ female interactions? & \multicolumn{2}{|c|}{ no } & \multicolumn{2}{|c|}{ yes } & \multicolumn{2}{|c|}{ no } & \multicolumn{2}{|c|}{ yes } \\
\hline Country dummies? & \multicolumn{2}{|c|}{ no } & \multicolumn{2}{|c|}{ no } & \multicolumn{2}{|c|}{ yes } & \multicolumn{2}{|c|}{ yes } \\
\hline Sample size & \multicolumn{2}{|c|}{13736} & \multicolumn{2}{|c|}{13736} & \multicolumn{2}{|c|}{13736} & \multicolumn{2}{|c|}{13736} \\
\hline
\end{tabular}

EPL Index is the OECD's index of strength of employment protection mandates for regular jobs.

Controls include age dummies, education, low test score dummy, immigrant dummy, and a female

dummy and female interactions with each of these variables. (Asymptotic) standard errors corrected for correlation within countries. Data are weighted using IALS sampling weights adjusted so that each country gets the same total weight. 
Table 9: Selected Logit Results for the Effects of Regular (EPL Index) and Temporary Employment Protection (Temp Index) on Permanent Employment, Wage and Salary Workers (partial derivatives at mean of dependent variable)

\begin{tabular}{|c|c|c|c|c|c|c|c|c|}
\hline & coef & asy se & coef & asy se & coef & asy se & coef & asy se \\
\hline EPL Index & 0.003 & 0.030 & 0.005 & 0.028 & --- & --- & --- & --- \\
\hline Temp Index & -0.021 & 0.021 & -0.018 & 0.019 & --- & --- & --- & --- \\
\hline EPL Index*Age 26-35 & 0.006 & 0.009 & 0.005 & 0.008 & 0.007 & 0.009 & 0.006 & 0.008 \\
\hline EPL Index*Age 36-45 & 0.019 & 0.020 & 0.018 & 0.018 & 0.025 & 0.019 & 0.024 & 0.017 \\
\hline EPL Index*Age 46-55 & 0.021 & 0.015 & 0.021 & 0.014 & 0.028 & 0.012 & 0.027 & 0.011 \\
\hline EPL Index*Age 56-65 & 0.019 & 0.041 & 0.026 & 0.038 & 0.035 & 0.044 & 0.042 & 0.040 \\
\hline EPL Index*Education & -0.001 & 0.002 & -0.001 & 0.002 & -0.002 & 0.003 & -0.002 & 0.002 \\
\hline EPL Index*Low Test Score & -0.025 & 0.022 & -0.027 & 0.022 & -0.021 & 0.025 & -0.024 & 0.024 \\
\hline EPL Index*Female & -0.009 & 0.002 & -0.011 & 0.002 & -0.008 & 0.002 & -0.009 & 0.002 \\
\hline EPL Index*Immigrant & -0.019 & 0.008 & -0.020 & 0.010 & -0.016 & 0.009 & -0.017 & 0.010 \\
\hline Temp Index*Age 26-35 & -0.006 & 0.006 & -0.006 & 0.006 & -0.006 & 0.005 & -0.006 & 0.006 \\
\hline Temp Index*Age 36-45 & 0.005 & 0.013 & 0.010 & 0.013 & 0.004 & 0.014 & 0.009 & 0.013 \\
\hline Temp Index*Age 46-55 & 0.013 & 0.009 & 0.017 & 0.009 & 0.012 & 0.006 & 0.017 & 0.007 \\
\hline Temp Index*Age 56-65 & 0.050 & 0.035 & 0.048 & 0.036 & 0.044 & 0.033 & 0.042 & 0.034 \\
\hline Temp Index*Education & 0.0002 & 0.002 & -0.0003 & 0.002 & 0.001 & 0.002 & 0.0003 & 0.002 \\
\hline Temp Index*Low Test Score & 0.008 & 0.011 & 0.009 & 0.011 & 0.004 & 0.014 & 0.005 & 0.014 \\
\hline Temp Index*Female & -0.004 & 0.003 & -0.001 & 0.003 & -0.004 & 0.003 & -0.001 & 0.004 \\
\hline Temp Index*Immigrant & 0.001 & 0.013 & 0.002 & 0.015 & -0.008 & 0.017 & -0.007 & 0.018 \\
\hline occup, ind ? & \multicolumn{2}{|c|}{ no } & \multicolumn{2}{|c|}{ yes } & \multicolumn{2}{|c|}{ no } & \multicolumn{2}{|c|}{ yes } \\
\hline (occup,ind)^ female interactions? & \multicolumn{2}{|c|}{ no } & \multicolumn{2}{|c|}{ yes } & \multicolumn{2}{|c|}{ no } & \multicolumn{2}{|c|}{ yes } \\
\hline Country dummies? & \multicolumn{2}{|c|}{ no } & \multicolumn{2}{|c|}{ no } & \multicolumn{2}{|c|}{ yes } & \multicolumn{2}{|c|}{ yes } \\
\hline Sample size & \multicolumn{2}{|c|}{13736} & \multicolumn{2}{|c|}{13736} & \multicolumn{2}{|c|}{13736} & \multicolumn{2}{|c|}{13736} \\
\hline
\end{tabular}

EPL Index is the OECD's index of strength of employment protection mandates for regular jobs.

Temp Index is the OECD's index of strength of employment protection mandates for temporary jobs.

Controls include age dummies, education, low test score dummy, immigrant dummy, and a female

dummy and female interactions with each of these variables. (Asymptotic) standard errors corrected for correlation within

countries. Data are weighted using IALS sampling weights adjusted so that each country gets the same total weight. 
Table 10: Selected Logit Results for the Effects of Employment Protection (EPL Index) on Permanent Employment with Adjustment for Selection into Employment, Wage and Salary Workers (partial derivatives at mean of dependent variable)

\begin{tabular}{|c|c|c|c|c|c|c|c|c|}
\hline & coef & se & coef & se & coef & se & coef & se \\
\hline EPL Index & -0.015 & 0.028 & -0.015 & 0.028 & --- & --- & --- & --- \\
\hline EPL Index*Age 26-35 & -0.011 & 0.005 & -0.011 & 0.005 & -0.007 & 0.006 & -0.006 & 0.007 \\
\hline EPL Index*Age 36-45 & 0.010 & 0.006 & 0.010 & 0.006 & 0.020 & 0.004 & 0.025 & 0.004 \\
\hline EPL Index*Age 46-55 & 0.020 & 0.005 & 0.020 & 0.005 & 0.031 & 0.009 & 0.037 & 0.008 \\
\hline EPL Index*Age 56-65 & 0.005 & 0.032 & 0.005 & 0.032 & 0.020 & 0.030 & 0.011 & 0.030 \\
\hline EPL Index*Education & -0.0002 & 0.002 & 0.000 & 0.002 & -0.0003 & 0.002 & -0.001 & 0.002 \\
\hline EPL Index*Low Test Score & -0.017 & 0.008 & -0.017 & 0.008 & -0.009 & 0.009 & -0.009 & 0.009 \\
\hline EPL Index*Female & -0.013 & 0.003 & -0.013 & 0.003 & -0.012 & 0.002 & -0.012 & 0.004 \\
\hline EPL Index*Immigrant & -0.006 & 0.007 & -0.006 & 0.007 & -0.009 & 0.009 & -0.008 & 0.009 \\
\hline occup, ind? & \multicolumn{2}{|c|}{ no } & \multicolumn{2}{|c|}{ yes } & \multicolumn{2}{|c|}{ no } & \multicolumn{2}{|c|}{ yes } \\
\hline (occup,ind)^ female interactions? & \multicolumn{2}{|c|}{ no } & \multicolumn{2}{|c|}{ yes } & \multicolumn{2}{|c|}{ no } & \multicolumn{2}{|c|}{ yes } \\
\hline Country dummies? & \multicolumn{2}{|c|}{ no } & \multicolumn{2}{|c|}{ no } & \multicolumn{2}{|c|}{ yes } & \multicolumn{2}{|c|}{ yes } \\
\hline Sample size & \multicolumn{2}{|c|}{11395} & \multicolumn{2}{|c|}{11395} & \multicolumn{2}{|c|}{11395} & \multicolumn{2}{|c|}{11395} \\
\hline
\end{tabular}

EPL Index is the OECD's index of strength of employment protection mandates for regular jobs.

Controls include age dummies, education, low test score dummy, immigrant dummy and a female dummy and female interactions with each of these variables. (Asymptotic) standard errors corrected for correlation within countries. Data are weighted using IALS sampling weights adjusted so that each country gets the same total weight. For description of

selectivity adjustment, see text. 
Table A1: Summary Statistics for Dependent Variables, by Country

Sample Includes All Adults (IALS)

Incidence of:

Temporary Permanent

Nonemployment Employment Employment
Sample Includes Only Employed Wage and Salary Workers

Incidence of:

$\begin{array}{cc}\text { Temporary } & \text { Temporary } \\ \text { Employment } & \text { Employment, } \\ \text { (IALS) } & 2000 \text { (OECD) }\end{array}$

A. Men

\begin{tabular}{|c|c|c|c|c|c|}
\hline Canada & 0.277 & 0.071 & 0.652 & 0.100 & 0.118 \\
\hline Finland & 0.362 & 0.066 & 0.572 & 0.123 & 0.145 \\
\hline Italy & 0.322 & 0.071 & 0.607 & 0.129 & 0.088 \\
\hline Netherlands & 0.280 & 0.067 & 0.653 & 0.101 & 0.115 \\
\hline Switzerland & 0.184 & 0.054 & 0.762 & 0.064 & 0.105 \\
\hline UK & 0.264 & 0.072 & 0.664 & 0.092 & 0.059 \\
\hline USA & 0.190 & 0.040 & 0.769 & 0.056 & 0.039 \\
\hline \multicolumn{6}{|l|}{ B. Women } \\
\hline Canada & 0.445 & 0.072 & 0.483 & 0.127 & 0.133 \\
\hline Finland & 0.404 & 0.113 & 0.484 & 0.205 & 0.209 \\
\hline Italy & 0.603 & 0.077 & 0.320 & 0.215 & 0.122 \\
\hline Netherlands & 0.549 & 0.069 & 0.382 & 0.156 & 0.172 \\
\hline Switzerland & 0.405 & 0.042 & 0.553 & 0.076 & 0.128 \\
\hline UK & 0.386 & 0.075 & 0.539 & 0.122 & 0.077 \\
\hline USA & 0.336 & 0.050 & 0.614 & 0.070 & 0.042 \\
\hline
\end{tabular}

Sources: IALS and OECD (2002, p. 138). IALS data are weighted using IALS sampling weights adjusted so that each country receives the same total weight. 
Table A2: Selected Multinomial Logit Results for the Interaction Effects of Employment Protection (EPL Index) and Collective Bargaining coverage (CB Cov)on Nonemployment, Temporary Employment and Permanent Employment (sample includes all adults)

\section{A. Probability of Permanent} Employment vs. Nonemployment (multinomial logit coeffs)

EPL Index*Age $26-35^{\star} \mathrm{CB}$ Cov EPL Index*Age $36-45^{\star} \mathrm{CB}$ Cov EPL Index*Age $46-55^{\star} \mathrm{CB}$ Cov EPL Index*Age $56-65^{\star} \mathrm{CB}$ Cov EPL Inde ${ }^{\star}$ Education ${ }^{\star} \mathrm{CB}$ Cov EPL Index*Low Test Score*CB Cov EPL Index*Female ${ }^{\star} \mathrm{CB}$ Cov EPL Index*Immigrant*CB Cov

Country dummies?

Sample size

\section{B. Probability of Permanent}

Employment vs. Temporary

\section{Employment (multinomial logit} coeffs)

EPL Index*Age $26-35^{\star} \mathrm{CB}$ Cov EPL Index*Age $36-45^{\star} \mathrm{CB}$ Cov EPL Inde ${ }^{\star}$ Age $46-55^{\star} \mathrm{CB}$ Cov EPL Index*Age 56-65* CB Cov EPL Index Education ${ }^{\star} \mathrm{CB}$ Cov EPL Index*Low Test Score*CB Cov EPL Index*Female ${ }^{\star} \mathrm{CB}$ Cov EPL Index*Immigrant ${ }^{\star} \mathrm{CB}$ Cov

Country dummies?

Sample size

$\begin{array}{ccc}\text { coef } & \text { ase } & \begin{array}{c}\text { relative risk } \\ \text { ratio }\end{array} \\ 1.149 & 0.620 & 3.154 \\ 1.411 & 0.458 & 4.099 \\ 1.259 & 0.538 & 3.521 \\ 0.362 & 0.666 & 1.436 \\ 0.194 & 0.103 & 1.214 \\ -0.187 & 0.259 & 0.830 \\ 0.156 & 0.448 & 1.168 \\ 0.051 & 0.399 & 1.052 \\ & \text { no } & \\ & 26159 & \end{array}$

coef
1.188
1.397
1.307
0.465
0.168
-0.430
0.135
-0.080

ase
0.603
0.463
0.522
0.664
0.095
0.305
0.456
0.256
yes
26159

relative risk

ratio

3.279

4.041

3.694

1.592

1.182

0.651

1.145

0.924

$\begin{array}{cccccc}\text { coef } & \text { asy se } & \begin{array}{c}\text { relative risk } \\ \text { ratio }\end{array} & \text { coef } & \text { asy se } & \begin{array}{c}\text { relative risk } \\ \text { ratio }\end{array} \\ 1.391 & 0.185 & 4.018 & 1.613 & 0.217 & 5.019 \\ 3.370 & 0.318 & 29.070 & 3.628 & 0.186 & 37.649 \\ 2.254 & 0.283 & 9.521 & 2.411 & 0.200 & 11.147 \\ 2.426 & 0.407 & 11.310 & 2.555 & 0.451 & 12.876 \\ 0.116 & 0.054 & 1.123 & 0.087 & 0.047 & 1.091 \\ 1.720 & 0.343 & 5.583 & 1.530 & 0.291 & 4.620 \\ -0.788 & 0.136 & 0.455 & -0.896 & 0.117 & 0.408 \\ -1.306 & 0.508 & 0.271 & -1.323 & 0.684 & 0.266 \\ & \text { no } & & & \text { yes } & \\ & 26159 & & & 26159 & \end{array}$

EPL Index is the OECD's index of strength of employment protection mandates for regular jobs, and CB Cov is collective bargaining coverage. Relative risk ratio equals exp(multinomial logit coefficient). Controls include age dummies, education, low test score dummy, immigrant dummy and a female dummy and female interactions with each of these variables, and interactions between $\mathrm{CB}$ Cov and each of these controls; in addition, in models excluding country dummies, EPL, CB Cov and EPL ${ }^{*} \mathrm{CB}$ Cov are included. Asymptotic standard errors are corrected for correlation within countries. Data are weighted using IALS sampling weights adjusted so that each country gets the same total weight. 
Table A3: Selected Logit Results for Demographic or Skill Interactions with Individual Components of the Permanent Protection Index Permanent Employment, Wage and Salary Workers (partial derivatives at mean of dep var)

\section{Interactions of Individual Protection Component \\ Variable and the Indicated Personal Characteristic}

$\begin{gathered}\text { Severance Pay after } 20 \\ \text { yrs }\end{gathered}$
Compensation, Unfair
Dismissal

coef ase coef ase coef ase coef ase

A. Occup, Industry, and their interactions with female excluded

Age26-35

Age36-45

Age 46-55

Age 56-65

Education

Low Test Score

Female

Immigrant

B. Occup, Industry, and their interactions with female included

Age26-35
Age36-45
Age 46-55
Age 56-65
Education
Low Test Score
Female
Immigrant

Individual Protection Component Variable

$$
\text { Dismissal }
$$

-0.020
-0.005
0.030
0.054
0.003
-0.001
-0.008

$-0.023$

$\begin{array}{ll}-0.017 & 0.009 \\ 0.003 & 0.023 \\ 0.040 & 0.022 \\ 0.048 & 0.047 \\ 0.002 & 0.002 \\ -0.002 & 0.017 \\ -0.005 & 0.009 \\ -0.023 & 0.021\end{array}$

$\begin{array}{lcc}0.010 & -0.002 & 0.009 \\ 0.024 & 0.025 & 0.020 \\ 0.022 & 0.038 & 0.009 \\ 0.049 & 0.071 & 0.023 \\ 0.002 & -0.00004 & 0.002 \\ 0.015 & -0.010 & 0.014 \\ 0.006 & -0.011 & 0.003 \\ 0.022 & -0.041 & 0.022\end{array}$

13736

13736

$\begin{array}{cc}-0.002 & 0.007 \\ 0.029 & 0.017 \\ 0.044 & 0.007 \\ 0.072 & 0.022 \\ -0.001 & 0.002 \\ -0.012 & 0.015 \\ -0.008 & 0.004 \\ -0.041 & 0.021\end{array}$

Mandatory Notice

0.049

0.185

0.115

0.205

$-0.033$

$-0.197$

$-0.068$

$-0.271$

0.193

0.119

0.224

$-0.032$

$-0.199$

$-0.053$

$-0.245$

\subsection{7}

0.107

0.055

0.129

0.004

0.092

0.015

0.105

0.055

0.100

0.051

0.115

0.003

0.096

0.017

0.107

13736
Procedural

Inconvenience Index

Entries based on a separate regression for each component indicator. Severance Pay and Unfair Dismissal pay refer to years of salary entitlement for a worker with 20 years of seniority. Mandatory Notice refers to years of notice required for someone with 20 years of seniority. Procedural Inconvenience Index is the OECD's index of procedural inconvenience, which has a range of 1-6.

Controls include age dummies, education, low test score dummy, immigrant dummy and a female dummy, female interactions with each of these variables (except the female dummy), and country dummies. Asymptotic standard errors corrected for correlation within countries. Data are weighted using IALS sampling weights adjusted so that each country gets the same total weight. 
Table A4: Selected Logit Results for the Effects of Employment Protection (EPL Index) on Permanent Employment, Italy Excluded, Wage and Salary Workers (derivatives at mean of dependent variable)

\begin{tabular}{|c|c|c|c|c|c|c|c|c|}
\hline & coef & asy se & coef & asy se & coef & asy se & coef & asy se \\
\hline EPL Index & -0.0020 & 0.0026 & -0.0018 & 0.0025 & --- & --- & -- & -- \\
\hline EPL Index*Age 26-35 & 0.0031 & 0.0009 & 0.0029 & 0.0007 & 0.0034 & 0.0011 & 0.0032 & 0.0009 \\
\hline EPL Index*Age 36-45 & 0.0050 & 0.0017 & 0.0050 & 0.0017 & 0.0056 & 0.0020 & 0.0056 & 0.0020 \\
\hline EPL Index*Age 46-55 & 0.0052 & 0.0013 & 0.0052 & 0.0012 & 0.0061 & 0.0018 & 0.0060 & 0.0018 \\
\hline EPL Index*Age 56-65 & 0.0063 & 0.0018 & 0.0064 & 0.0019 & 0.0071 & 0.0022 & 0.0071 & 0.0023 \\
\hline EPL Index*Education & -0.0002 & 0.0002 & -0.0002 & 0.0002 & -0.0002 & 0.0002 & -0.0002 & 0.0002 \\
\hline EPL Index*Low Test Score & -0.0026 & 0.0018 & -0.0024 & 0.0017 & -0.0025 & 0.0019 & -0.0024 & 0.0018 \\
\hline EPL Index*Female & -0.0018 & 0.0010 & -0.0017 & 0.0009 & -0.0014 & 0.0008 & -0.0013 & 0.0006 \\
\hline EPL Index*Immigrant & -0.0017 & 0.0010 & -0.0018 & 0.0011 & -0.0023 & 0.0010 & -0.0024 & 0.0010 \\
\hline occup, ind? & \multicolumn{2}{|c|}{ no } & \multicolumn{2}{|c|}{ yes } & \multicolumn{2}{|c|}{ no } & \multicolumn{2}{|c|}{ yes } \\
\hline (occup,ind)^ female interactions? & \multicolumn{2}{|c|}{ no } & \multicolumn{2}{|c|}{ yes } & \multicolumn{2}{|c|}{ no } & \multicolumn{2}{|c|}{ yes } \\
\hline Country dummies? & \multirow{2}{*}{\multicolumn{2}{|c|}{$\begin{array}{c}\text { no } \\
12446\end{array}$}} & \multicolumn{2}{|c|}{ no } & \multicolumn{2}{|c|}{ yes } & \multicolumn{2}{|c|}{ yes } \\
\hline Sample size & & & \multicolumn{2}{|c|}{12446} & \multicolumn{2}{|c|}{12446} & \multicolumn{2}{|c|}{12446} \\
\hline
\end{tabular}

EPL Index is the OECD's index of strength of employment protection mandates for regular jobs.

Controls include age dummies, education, low test score dummy, immigrant dummy and a female dummy and female interactions with each of these variables. (Asymptotic) standard errors corrected for correlation within countries. Data are weighted using IALS sampling weights adjusted so that each country gets the same total weight. 
Table A5: Selected Logit Results for the Effects of Employment Protection (EPL Index) on Permanent Employment, Excluding Those Age 16-25, Wage and Salary Workers (derivatives at mean of dependent variable)

$\begin{array}{lcccccccc} & \text { coef } & \text { asy se } & \text { coef } & \text { asy se } & \text { coef } & \text { asy se } & \text { coef } & \text { asy se } \\ \text { EPL Index } & -0.0101 & 0.0250 & -0.0092 & 0.0207 & --- & --- & -- & --- \\ \text { EPL Index*Age 36-45 } & 0.0183 & 0.0066 & 0.0209 & 0.0064 & 0.0235 & 0.0072 & 0.0260 & 0.0070 \\ \text { EPL Index*Age 46-55 } & 0.0247 & 0.0085 & 0.0286 & 0.0096 & 0.0321 & 0.0073 & 0.0362 & 0.0087 \\ \text { EPL Index*Age 56-65 } & 0.0471 & 0.0158 & 0.0520 & 0.0144 & 0.0638 & 0.0153 & 0.0676 & 0.0140 \\ \text { EPL Index*Education } & -0.0009 & 0.0015 & -0.0010 & 0.0013 & -0.0007 & 0.0016 & -0.0009 & 0.0014 \\ \text { EPL Index*Low Test Score } & -0.0179 & 0.0079 & -0.0169 & 0.0081 & -0.0133 & 0.0095 & -0.0134 & 0.0096 \\ \text { EPL Index*Female } & -0.0129 & 0.0036 & -0.0111 & 0.0047 & -0.0105 & 0.0039 & -0.0082 & 0.0054 \\ \text { EPL Index*Immigrant } & -0.0074 & 0.0056 & -0.0106 & 0.0062 & -0.0125 & 0.0087 & -0.0157 & 0.0089\end{array}$

occup, ind?

(occup,ind)* female interactions?

Country dummies?

Sample size

\begin{tabular}{cccc} 
no & yes & no & yes \\
no & yes & no & yes \\
no & no & yes & yes \\
11614 & 11614 & 11614 & 11614 \\
\hline
\end{tabular}

EPL Index is the OECD's index of strength of employment protection mandates for regular jobs.

Controls include age dummies, education, low test score dummy, immigrant dummy and a female dummy and female interactions with each of these variables. (Asymptotic) standard errors corrected for correlation within countries. Data are weighted using IALS sampling weights adjusted so that each country gets the same total weight. 